\title{
Assimilation of Satellite-Derived Soil Moisture for Improved Forecasts of the Great Plains Low-Level Jet $\mathscr{O}$
}

\author{
Craig R. Ferguson, ${ }^{a, b}$ Shubhi Agrawal, ${ }^{a, b}$ Mark C. Beauharnois, ${ }^{a}$ Geng Xia, ${ }^{c}$ \\ D. Alex Burrows, ${ }^{\mathrm{a}, \mathrm{b}}$ AND LANCE F. Bosart ${ }^{\mathrm{b}}$ \\ ${ }^{a}$ Atmospheric Sciences Research Center, University at Albany, State University of New York, Albany, New York \\ ${ }^{\mathrm{b}}$ Department of Atmospheric and Environmental Sciences, University at Albany, State University of \\ New York, Albany, New York \\ ${ }^{\mathrm{c}}$ National Renewable Energy Laboratory, U.S. Department of Energy, Golden, Colorado
}

(Manuscript received 8 June 2020, in final form 23 September 2020)

\begin{abstract}
In the context of forecasting societally impactful Great Plains low-level jets (GPLLJs), the potential added value of satellite soil moisture (SM) data assimilation (DA) is high. GPLLJs are both sensitive to regional soil moisture gradients and frequent drivers of severe weather, including mesoscale convective systems. An untested hypothesis is that SM DA is more effective in forecasts of weakly synoptically forced, or uncoupled GPLLJs, than in forecasts of cycloneinduced coupled GPLLJs. Using the NASA Unified Weather Research and Forecasting (NU-WRF) Model, 75 GPLLJs are simulated at 9-km resolution both with and without NASA Soil Moisture Active Passive SM DA. Differences in modeled SM, surface sensible ( $\mathrm{SH}$ ) and latent heat (LH) fluxes, 2-m temperature (T2), 2-m humidity (Q2), PBL height (PBLH), and 850-hPa wind speed (W850) are quantified for individual jets and jet-type event subsets over the south-central Great Plains, as well as separately for each GPLLJ sector (entrance, core, and exit). At the GPLLJ core, DA-related changes of up to $5.4 \mathrm{~kg} \mathrm{~m}^{-2}$ in SM can result in T2, Q2, LH, SH, PBLH, and W850 differences of $0.68^{\circ} \mathrm{C}, 0.71 \mathrm{~g} \mathrm{~kg}^{-2}, 59.9 \mathrm{~W} \mathrm{~m}^{-2}, 52.4 \mathrm{~W} \mathrm{~m}^{-2}$, $240 \mathrm{~m}$, and $4 \mathrm{~m} \mathrm{~s}^{-1}$, respectively. W850 differences focus along the jet axis and tend to increase from south to north. Jet-type differences are most evident at the GPLLJ exit where DA increases and decreases W850 in uncoupled and coupled GPLLJs, respectively. Data assimilation marginally reduces negative wind speed bias for all jets, but the correction is greater for uncoupled GPLLJs, as hypothesized.
\end{abstract}

KEYWORDS: Atmosphere-land interaction; Soil moisture; Data assimilation; Model errors; Model initialization; Numerical weather prediction/forecasting

\section{Introduction}

Probing the potential of accurate soil moisture initialization to improve streamflow and subseasonal to seasonal temperature and precipitation forecasts has been an active area of research within the hydrologic (e.g., Baugh et al. 2020; Day 1985; Mahanama et al. 2008; Maurer and Lettenmaier 2003) and atmospheric (e.g., Beljaars et al. 1996; Dirmeyer et al. 2018; Koster et al. 2004; Namias 1960; Shukla and Mintz 1982; van den Hurk et al. 2012) research communities for decades. Modulated by site topography, soils, vegetation and net radiative flux, soil moisture plays a key role in determining rainfall/runoff and Bowen ratios at a point (e.g., Koster and Mahanama 2012). Changes in Bowen ratio affect sensible weather (i.e., 2-m temperature and humidity), atmospheric stability and the diurnal evolution of the planetary boundary layer (PBL), clouds, and local convective rainfall (e.g., Findell and Eltahir 2003) — a series of linked interactions collectively referred to as the local landatmosphere coupling process chain (Santanello et al. 2018). When local land-atmosphere interactions scale-up in time and

Supplemental information related to this paper is available at the Journals Online website: https://doi.org/10.1175/MWR-D-200185.s1.

Corresponding author: Craig R. Ferguson, crferguson@albany.edu. space, they can affect regional precipitation recycling, drought, and heatwave intensity (e.g., Agrawal et al. 2019; Dirmeyer and Brubaker 1999; Miralles et al. 2019; Seneviratne et al. 2010; Yang et al. 2019). Consequently, soil moisture is recognized as an essential climate variable by the Global Climate Observing System (WMO 2016). While ESA's Soil Moisture and Ocean Salinity (SMOS; Kerr et al. 2016) and NASA's Soil Moisture Active-Passive (SMAP; Entekhabi et al. 2014) constitute the only dedicated soil moisture satellite missions, a multisatellite passive microwave radiometer record dating back to 1978 has long been the focus of soil moisture remote sensing studies (e.g., Gruber et al. 2019; Karthikeyan et al. 2017; Njoku and Entekhabi 1996).

Despite considerable effort from the scientific community, the struggle to realize appreciable atmospheric and hydrologic forecast skill gains from soil moisture data assimilation is ongoing (e.g., de Lannoy et al. 2016; Draper and Reichle 2019). Commonplace uncoupled land model assimilation experiments, when successful, have resulted in only modest skill enhancements to column soil moisture and streamflow estimates (e.g., Draper et al. 2012; Kumar et al. 2015, 2014; Lievens et al. 2015; Yin et al. 2019). Similarly, results from a limited number of fully coupled model soil moisture data assimilation (DA) experiments have demonstrated marginal benefit to short-term 2-m air temperature and humidity forecasts (i.e., Lin and $\mathrm{Pu}$ 2019, 2020). Proving added value of soil moisture DA in regions such as the conterminous United States, where soil 
moisture is already well-constrained via the assimilation of dense weather radar network products (e.g., Lakshmanan and Humphrey 2014), can be exceedingly difficult. Presently, satellite soil moisture is not assimilated operationally into any coupled U.S. numerical weather prediction model, of any range (short, medium, or subseasonal-seasonal).

Prior studies have likely underestimated soil moisture DA's added benefit to forecasting systems because they quantified added value in a time- and area-averaged Eulerian reference frame. The potential for strong land-atmosphere interactions and consequently the potential impact of soil moisture DA on weather forecasts vary substantially over time as a function of weather regime (e.g., Ford et al. 2015; Song et al. 2016). And perhaps more importantly, the societal benefit of weather forecast improvements is not timeconstant, but instead maximized during extremes. A more pragmatic assessment of the added value of soil moisture DA would give additional weight to events of opportunity such as Great Plains low-level jets (GPLLJs) when the land's potential impact on the atmosphere and the potential for extreme weather are both high. GPLLJs are both sensitive to regional soil moisture gradients (e.g., Arcand et al. 2019; Campbell et al. 2019; Fast and McCorcle 1990) and primary drivers of the Great Plains's warm-season extreme wind and rainfall events, including severe mesoscale convective systems (Houze 2018; Song et al. 2019).

The GPLLJ may be described by the combined mechanisms of Blackadar (1957) and Holton (1967) (e.g., Du and Rotunno 2014; Parish 2017; Shapiro et al. 2016). The Holton (1967) mechanism links the GPLLJ's diurnal oscillation to diurnal shifts in the wind direction/lower tropospheric temperature gradient across the region's east-west sloping terrain. During the daytime, insolation warms the elevated western Great Plains faster than the air to the east, which establishes a westeast temperature gradient. At nighttime, the opposite is true: the elevated ground to the west cools more quickly than the air to the east, and an east-west temperature gradient is established. The Blackadar (1957) mechanism describes GPLLJ formation by the resultant inertial oscillation after nocturnal decoupling of the PBL (i.e., loss of surface friction). An example of the Blackadar (1957) causal chain would be as follows: increased sensible heating over dry soils $\rightarrow$ increased lower tropospheric warming, stronger turbulent eddies, and deeper PBL $\rightarrow$ delayed collapse of the PBL at a time with stronger ageostrophic winds $\rightarrow$ stronger inertial oscillation $\rightarrow$ greater wind maximum at a later time. Idealized studies have demonstrated that changes in soil moisture variations can modulate both Blackadar (1957) and Holton (1967) forcing mechanisms and thereby affect GPLLJ strength and positioning (e.g., Campbell et al. 2019). Theoretically, forecasts of weakly synoptically forced, or uncoupled GPLLJs, which occur in the presence of a large persistent ridge over the central United States and weak flow aloft in the southern Great Plains, will benefit most from soil moisture DA. In the absence of strong upper-level synoptic forcing, land-atmosphere interactions should dominate uncoupled GPLLJ forcing and predictability. By contrast, forecasts of more transient cyclone-induced, or coupled GPLLJs, will benefit less from soil moisture DA.
In this study, we quantify the added value of NASA SMAP soil moisture DA (SMAP DA) in the context of short-term (6$24 \mathrm{~h})$ GPLLJ forecasts. Using a weakly coupled NASA Unified Weather Research and Forecasting (NU-WRF; Peters-Lidard et al. 2015) Model-Land Information System (LIS; Kumar et al. 2006; Peters-Lidard et al. 2007) modeling configuration, we simulate 75 GPLLJs - 43 uncoupled and 32 coupled-between 2015 and 2017 both with and without SMAP DA. We quantify differences between the two simulations for the following fields: soil moisture, precipitation, surface sensible and latent heat flux, 2-m temperature and humidity, PBL height (PBLH), and $850-\mathrm{hPa}$ wind speed (W850). SMAP soil moisture products have been shown to yield the highest accuracy among available AMSR-E, AMSR-2, ASCAT, and SMOS satellite-derived products as measured by conventional statistics (e.g., Kim et al. 2018), triple collocation (e.g., Chen et al. 2018), and information theory (i.e., Kumar et al. 2018). The analyses presented here specifically address 1) how SMAP DA impacts wind speed forecasts along the jet axis and 2) whether its impact on wind speed forecasts differs significantly between coupled and uncoupled GPLLJs. This study marks the first time that the added value of SMAP DA has been quantified in an object-based (e.g., jet) framework. The GPLLJ jet mapping algorithm that made this work feasible is described in the online supplemental material (in Figs. S1-S3).

\section{Data and methods}

\section{a. GPLLJ case selection and dynamical classification}

We selected 75 GPLLJ events for analysis from the period of May-September 2015-17 during SMAP's first three years of orbit. GPLLJs were first identified using Modern-Era Retrospective Analysis for Research and Applications, version 2 (MERRA-2; Gelaro et al. 2017), $0.5^{\circ} \times 0.625^{\circ}$ (latitude $\times$ longitude) reanalysis according to the following criteria of Montini et al. (2019), which must be satisfied simultaneously at a grid point: 1) 3-hourly W850 exceeds its monthly 75th percentile, 2) 3-hourly $850-700-\mathrm{hPa}$ wind (W850-W700) shear exceeds its monthly 75th percentile, and 3) W850 direction is between $113^{\circ}$ and $247^{\circ}$. For a given day to be added to the GPLLJ sample set, at least $20 \%$ of grid points within the south-central Great Plains (SCP; $29.75^{\circ}-40.25^{\circ} \mathrm{N}$, $\left.102.8125^{\circ}-93.4375^{\circ} \mathrm{W}\right)$ must satisfy all three criteria at one or more 3-hourly time steps between 0000 and 1200 UTC. The 0000, 0300, 0600, 0900, and 1200 UTC monthly W850 and W850-W700 shear thresholds were computed from the 1980-2019 time series. From the initial GPLLJ sample set, we filtered out 17 days with tropical cyclone activity in either the Gulf of Mexico or off the eastern U.S coast and 4 days for which atmospheric boundary forcing data were not available [see section $2 \mathrm{~b}(3)$ ].

Each of the 75 GPLLJs selected was classified as either coupled or uncoupled to the upper-atmospheric jet stream (e.g., Chen and Kpaeyeh 1993; Uccellini 1980; Wang and Chen 2009). Uncoupled GPLLJs occur under large-scale zonal flow patterns with a central ridge, whereas coupled GPLLJs occur with an upstream trough of varying strength (see 
TABLE 1. Listing of the 75 jet cases analyzed in this study according to dynamical classification. Superscripts denote cases for which the jet entrance (E), core (C), or exit (X) are located outside the modeled domain. The number of all-, uncoupled-, and coupled-GPLLJ jet samples available for each sector is as follows: E: 54/33/21 (all/uncoupled/coupled); C: 74/43/31 (all/uncoupled/coupled); X: 64/37/27 (all/uncoupled/coupled).

\begin{tabular}{|c|c|c|c|c|c|}
\hline \multicolumn{3}{|c|}{ Uncoupled LLJ cases $(n=43)$} & \multicolumn{3}{|c|}{ Coupled LLJ cases $(n=32)$} \\
\hline $2015(n=19)$ & $2016(n=18)$ & $2017(n=6)$ & $2015(n=5)$ & $2016(n=13)$ & $2017(n=14)$ \\
\hline 3 May $^{X}$ & 9 Jun & 3 May & 14 May $^{\mathrm{E}}$ & 7 May & 7 May $^{X}$ \\
\hline 4 May & 10 Jun & $10 \operatorname{Jun}^{\mathrm{X}}$ & $16 \mathrm{May}^{\mathrm{E}}$ & 8 May $^{\mathrm{E}}$ & 8 May $^{\mathrm{E}, \mathrm{X}}$ \\
\hline 12 Jun & 16 Jun & $28 \operatorname{Jun}^{\mathrm{X}}$ & 5 Jun & 9 May $^{\mathrm{E}}$ & 9 May \\
\hline $21 \operatorname{Jun}^{\mathrm{E}}$ & 22 Jun & 29 Jun & 14 Sep & $11 \mathrm{May}^{\mathrm{E}}$ & 14 May \\
\hline $22 \operatorname{Jun}^{\mathrm{E}}$ & $6 \mathrm{Jul}$ & $12 \mathrm{Jul}$ & 15 Sep & $22 \mathrm{May}^{\mathrm{E}, \mathrm{X}}$ & 15 May \\
\hline 23 Jun & $7 \mathrm{Jul}$ & 6 Aug & & 23 May & 16 May $^{\mathrm{E}}$ \\
\hline 24 Jun & $8 \mathrm{Jul}$ & & & 25 May & 26 May \\
\hline 25 Jun & $11 \mathrm{Jul}^{\mathrm{E}}$ & & & 27 May $^{\mathrm{E}}$ & 11 Jun \\
\hline $1 \mathrm{Jul}$ & $12 \mathrm{Jul}^{\mathrm{E}, \mathrm{X}}$ & & & 23 Aug & 12 Jun \\
\hline $2 \mathrm{Jul}^{\mathrm{E}}$ & $13 \mathrm{Jul}^{\mathrm{E}}$ & & & $6 \mathrm{Sep}$ & 13 Jun \\
\hline $6 \mathrm{Jul}^{\mathrm{E}}$ & $14 \mathrm{Jul}^{\mathrm{E}}$ & & & 7 Sep & $14 \operatorname{Jun}^{\mathrm{X}}$ \\
\hline $7 \mathrm{Jul}^{\mathrm{E}}$ & $17 \mathrm{Jul}$ & & & $23 \operatorname{Sep}^{\mathrm{E}, \mathrm{C}, \mathrm{X}}$ & $16 \mathrm{Aug}^{\mathrm{E}}$ \\
\hline $11 \mathrm{Jul}$ & $18 \mathrm{Jul}$ & & & 24 Sep & 15 Sep \\
\hline $18 \mathrm{Jul}$ & $1 \operatorname{Aug}^{X}$ & & & & $16 \mathrm{Sep}$ \\
\hline $19 \mathrm{Jul}$ & 2 Aug & & & & \\
\hline $28 \mathrm{Jul}$ & 11 Aug & & & & \\
\hline 18 Aug & 24 Aug & & & & \\
\hline $22 \mathrm{Aug}^{\mathrm{E}}$ & $12 \operatorname{Sep}^{\mathrm{X}}$ & & & & \\
\hline 27 Aug & & & & & \\
\hline
\end{tabular}

Burrows et al. 2019, their Fig. 1). To classify the jets, we applied the dynamically derived objective jet classification method of Burrows et al. (2019), which augments the conventional Bonner-Whiteman (Bonner 1968; Whiteman et al. 1997) lowlevel jet wind speed and vertical wind shear criteria with a 500hPa wave-amplitude criterion. Specifically, May-September wave-amplitude thresholds of Burrows et al. (2019), defined from the 110-year (1901-2010) 125-km European Centre for Medium-Range Weather Forecasts Coupled Earth Reanalysis of the twentieth century (CERA-20 C; Laloyaux et al. 2018), are spatially downscaled and applied to MERRA-2 500-hPa geopotential height fields. As a final step, all objective dynamical classifications were verified using manual weather map analysis.

It is important to note that jet classification can vary along the axis of a given jet. GPLLJs tend to transition from strongly uncoupled to strongly coupled from south to north. The northern extent of purely uncoupled events tends to lie between $40^{\circ}$ and $45^{\circ} \mathrm{N}$, correspondent with the southern edge of the hemispheric baroclinic zone, which advances northward from May to August and begins its retreat southward in September (e.g., Burrows et al. 2020, their Figs. 1 and 2). The GPLLJs in this study are classified according to their vertical wind shear profile and synoptic environment in the SCP.

Table 1 provides a listing of all 75 simulated case days grouped according to their dynamical jet classification. Figure 1 provides a graphical summary of the 75 jet tracks and a breakdown of the monthly coupled and uncoupled GPLLJ frequencies. The monthly distribution of sampled uncoupled and coupled GPLLJs (Fig. 1b) is consistent with the long-term (1901-2010) seasonal climatology of jet-class frequencies reported by Burrows et al. (2019).

\section{b. Modeling}

\section{1) LIS}

The NASA LIS is an interagency test bed for land surface modeling with support for ensemble Kalman filter (EnKF; Burgers et al. 1998; Evensen 1994) land data assimilation (Kumar et al. 2019, 2014). In this study, LIS, version 7.2 (v7.2), was used to run the Noah v3.6 land model (Ek et al. 2003) over the region spanning $27^{\circ}-49^{\circ} \mathrm{N}$ and $126^{\circ}-71^{\circ} \mathrm{W}$ at $0.08^{\circ} \times 0.08^{\circ}$ (latitude $\times$ longitude) resolution. This was done both with and without SMAP Enhanced Level 3 (L3) 9-km soil moisture (O'Neill et al. 2018) DA for the period from 1 April 2015 to 30 September 2017. Noah v3.6 was run using a 30-min time step and standard four-soil-layer configuration with layer thicknesses of $0.1,0.3,0.6$, and $1.0 \mathrm{~m}$, from surface to bottom boundary. LIS v7.2 was customized to support the following more modern input datasets: Princeton University's hourly, $0.03125^{\circ}$ meteorological forcing for the conterminous United States (PUMET; Pan et al. 2016); real-time 4-day, 500-m Moderate Resolution Imaging Spectroradiometer (MODIS) leaf area index (MCD15A3H Collection 6; Myneni et al. 2015); real-time 8-day, 250-m MODIS NDVI-based greenness vegetation fraction (MOD13Q1/MYD13Q1 Collection 6; Didan 2015a,b); real-time 8-day, 1-km MODIS gap-filled snow-free surface shortwave albedo (MCD43GF Collection 5; Sun et al. 2017); and the 2011 National Land Cover Database 40-class land-cover dataset (Yang et al. 2018). Important is that PUMET enables us to run LIS at a finer resolution than LIS-supported $0.125^{\circ} \times 0.125^{\circ}$ (latitude $\times$ longitude) North American Land Data Assimilation System Phase 2 meteorological forcing (Xia et al. 2012a,b), and the real-time MODIS datasets capture fine spatiotemporal vegetation dynamics that 

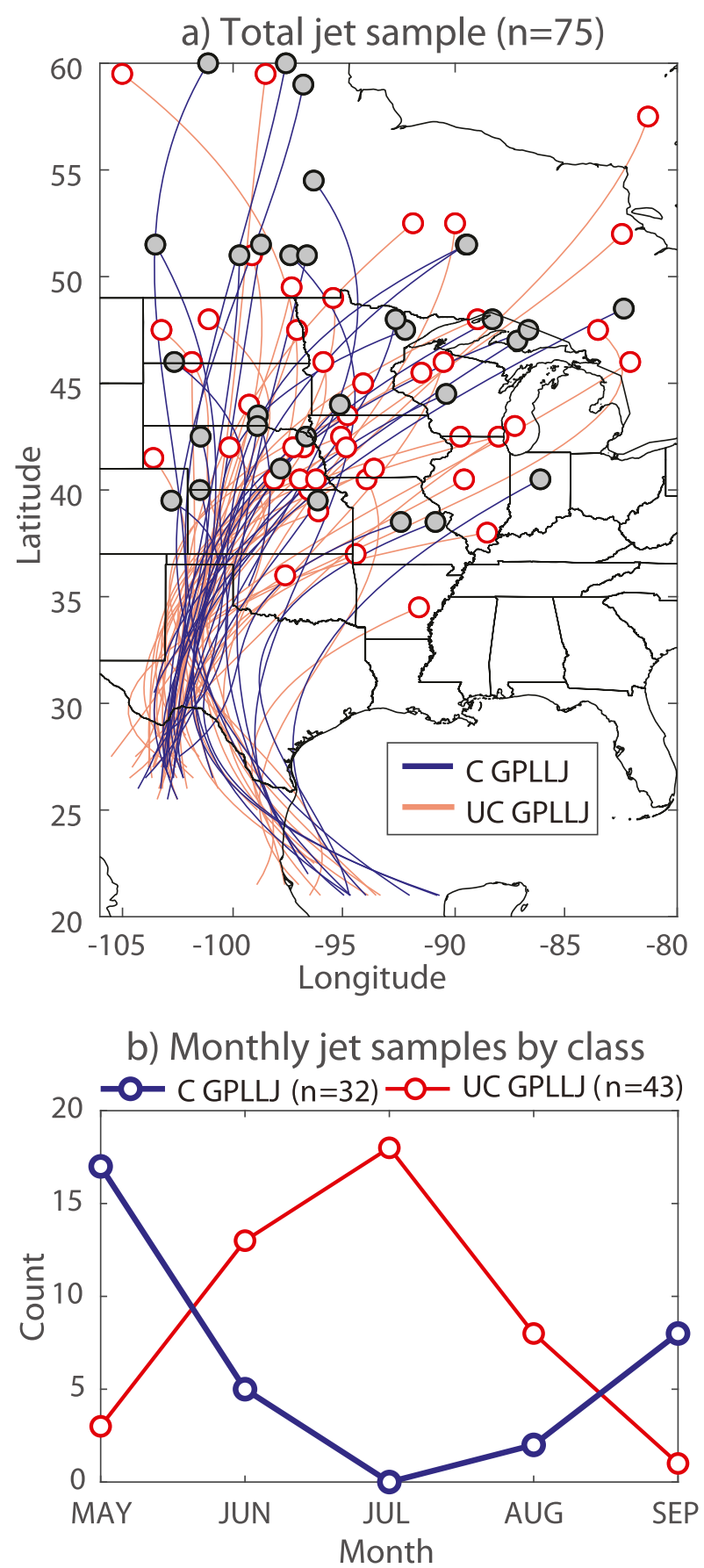

FIG. 1. (a) Tracks of this study's Great Plains low-level jet (GPLLJ) sample colored according to dynamical classification (coupled: blue; uncoupled: red) and (b) a summary of jet count by month and class. Uncoupled (UC) and coupled (C) jet exit sectors are marked by open red circles and filled gray circles, respectively. Jets are dynamically classified using MERRA-2 500-hPa geopotential height (Z500) data, following the approach of Burrows et al. (2019).

would be absent using the LIS-supported monthly mean climatological vegetation fields. Additional data-processing details are provided in the online supplemental material.

\section{2) SMAP/LIS-DA}

SMAP's L-band $(1.4 \mathrm{GHz})$ passive radiometer is sensitive to signal attenuation due to radio frequency interference (e.g., Njoku et al. 2003; Soldo et al. 2016), dense vegetation, large surface water fractions, active precipitation, and snow-covered and/or frozen ground. Sensor look angle can also limit retrievals in regions of steep terrain (i.e., O'Neill et al. 2020). Therefore, SMAP data are only used when data quality is assured (i.e., retrieval_qual_flag, bit $0=0$ ). At grids for which morning/descending overpass retrievals are either not available or of insufficient quality, quality-cleared retrievals from the evening/ascending overpass are infilled.

SMAP morning/descending overpass Single Channel Algorithm $\mathrm{V}$-pol (SCA-V) soil moisture retrievals are assimilated into LIS after first being spatially interpolated from Equal-Area Scalable Earth grid to the modeled regular latitude/longitude grid and subsequently undergoing bias correction by cumulative distribution function (CDF) matching to the no-DA AprilSeptember 2015-17 lumped soil moisture CDF (Reichle and Koster 2004). A pair of SMAP and Noah soil moisture CDFs is constructed for each grid using a two-grid sampling radius. Of SMAP's five operational surface soil moisture retrieval algorithms, the SCA-V algorithm is found to result in the best overall performance, with a morning/descending overpass unbiased RMSE of $0.037 \mathrm{~m}^{3} \mathrm{~m}^{-3}$, bias of $-0.001 \mathrm{~m}^{3} \mathrm{~m}^{-3}$, and correlation of 0.821 based on intercomparisons conducted over three years (April 2015-March 2018) at SMAP's 15 core validation sites (Jackson et al. 2018; their Table 8.2).

Using LIS, a classic perturbed observation EnKF of 20 members is generated at each grid by adding noise to selected meteorological forcing fields, Noah modeled soil moisture, and SMAP L3 soil moisture. Additive perturbations with a mean of 0 and standard deviation of $0.02 \mathrm{~m}^{3} \mathrm{~m}^{-3}$ are applied to the SMAP L3 soil moisture prior to CDF-based rescaling. Important is that SMAP data are only assimilated when it is both quality assured and consistent with the modeled land state. LIS-issued flags must indicate that there is no precipitation at the time of overpass, no snow cover, and no frozen soil or pore ice at any soil layer for SMAP data to be assimilated. This model situational check is necessary because, for example, even if SMAP soil moisture is deemed of sufficient quality, it would be unrealistic to use this data to update soil moisture under a modeled snowpack. Separately, precipitation and downward shortwave radiation (SW) are perturbed with multiplicative perturbations of mean $=1$ and standard deviation $=$ 0.3 and 0.5 , respectively. Additive perturbations with a mean of 0 and standard deviation of $50 \mathrm{~W} \mathrm{~m}^{-2}$ are applied to the longwave radiation ( $\mathrm{LW})$. Last, additive perturbations with a mean of 0 and standard deviation of $5.0 \times 10^{-3}, 1.1 \times 10^{-4}$, $0.6 \times 10^{-5}$, and $0.4 \times 10^{-5} \mathrm{~m}^{3} \mathrm{~m}^{-3}$ are applied to the modeled soil moisture prognostic variables at each of Noah's four soil layers $\mathrm{SM}_{1}-\mathrm{SM}_{4}$, respectively.

The meteorological forcing, Noah state soil moisture, and SMAP CDF-matched soil moisture fields are perturbed according to the so-called GMAO scheme described in Reichle et al. (2007) at 1-, 3-, and 6-h frequencies, respectively. Correlation time scales of 24 and $12 \mathrm{~h}$, respectively, are imposed on the 
TABLE 2. Abbreviated physics configuration of the NU-WRF simulations. For the complete model configuration (i.e., namelist), see the online supplemental material.

\begin{tabular}{lll}
\hline \hline Parameterization scheme & \multicolumn{1}{c}{ Selection } & \multicolumn{1}{c}{ Reference(s) } \\
\hline Microphysics & Thompson aerosol-aware & Thompson and Eidhammer (2014) \\
Cumulus & None & \\
Shortwave radiation & RRTMG & Iacono et al. (2008) \\
Longwave radiation & RRTMG & Iacono et al. (2008) \\
Surface layer & Revised MM5 Monin-Obukhov & Jiménez et al. (2012) \\
Planetary boundary layer & YSU & Hong et al. (2006) \\
Land & LIS-Noah v3.6 & Ek et al. (2003) and Peters-Lidard et al. (2007) \\
\hline
\end{tabular}

forcing and state soil moisture fields. Cross correlations $\rho$ are also prescribed between related variables: $\rho\left(\mathrm{SM}_{1}, \mathrm{SM}_{2}\right)=0.6$, $\rho\left(\mathrm{SM}_{1}, \mathrm{SM}_{3}\right)=0.4, \rho\left(\mathrm{SM}_{1}, \mathrm{SM}_{4}\right)=0.2, \rho(\mathrm{SW}, P)=-0.8$ $\rho(\mathrm{SW}, \mathrm{LW})=-0.5$, and $\rho(\mathrm{LW}, P)=0.5$, where $P$ is precipitation. To avoid the introduction of biases through perturbations, the perturbation bias-correction algorithm of Ryu et al. (2009) is implemented. The EnKF approach described is fully supported in out-of-the-box LIS v7.2, and the specific implementation details (see above) are largely consistent with those of Kumar et al. (2014; their Table 1).

Both LIS DA and no-DA simulations are initialized from the 1 April 2015 restart file from the same cycled 18.5-yr spinup simulation. For the spinup, the model was run from a cold-start on 1 October 2007 until 1 October 2017 and the restart files from this run were used to initialize a second spinup simulation spanning 1 October 2007-31 March 2015. Daily 1300 UTC restart files from the LIS DA and no-DA simulations were saved for use in the initialization of NU-WRF simulations (see next section). LIS DA restart files specify the 20member ensemble mean states, including $\mathrm{SM}_{1}-\mathrm{SM}_{4}$. SMAP DA is conducted hourly, contingent upon coverage, and only during the warm-season (April-September). Although SMAP overpass time is nominally 0600 and $1800 \mathrm{LT}$, the UTC time of overpass across CONUS varies. For reference, the LIS model configuration file is provided in the online supplemental material.

\section{3) NU-WRF}

NU-WRF is built upon the community Advanced Research WRF core (Skamarock et al. 2005) and fully integrates LIS, along with Goddard Space Flight Center atmospheric chemistry, radiation, and microphysics schemes into a single modeling framework. In this study, we use NU-WRF, version 9.1 (v9.1), which includes the WRF v3.9.1 atmospheric model coupled to LIS v7.2. The key physical schemes of the coupled model configuration are listed in Table 2, and the complete namelist model configuration file is provided in the online supplemental material. WRF is run on the same domain and horizontal grid as the LIS land-only simulations (i.e., $0.08^{\circ} \times 0.08^{\circ}$ latitude $\times$ longitude) and with 60 vertical levels from the surface to $100 \mathrm{hPa}$, including 10 levels below $500 \mathrm{~m}$ and 15 levels below $1000 \mathrm{~m}$. The WRF land initialization works seamlessly because LIS and WRF are running the same Noah v3.6 model configuration on the same horizontal grid and with the same ancillary soil and vegetation parameters.
Separate WRF SMAP DA and no-DA simulations are produced for each GPLLJ case. WRF is initialized at 1300 UTC (0800 LT in Oklahoma) on the day prior to each GPLLJ case (hereinafter Day 0). Initial surface soil and vegetative states and soil temperature and moisture profiles are taken from the LIS-Noah v3.6 offline uncoupled DA and no-DA simulations described in the previous section. Initial atmospheric temperature, humidity, and wind profiles are taken from the $13-\mathrm{km}$ Rapid Refresh (RAP; Benjamin et al. 2016) analysis. For 24-h after initialization, or until 1300 UTC on the following day (hereinafter Day 1), the WRF simulation runs independently of the offline uncoupled LIS simulations, constrained only by 3-hourly lateral atmospheric boundary conditions prescribed from RAP analysis. Because no additional soil moisture DA is performed during the 24-h WRF simulation after initialization, this setup is widely referred to as weakly coupled DA (e.g., Lin and Pu 2018). NCEP RAP v2 (implemented 25 February 2014) and v3 (implemented 23 August 2016) operational analysis data are used, except for the 12 June 2015 case for which only NOAA/ESRL experimental RAP v3 analysis is available. RAP assimilates a wide range of observational data, including and of particular relevance here: 2-m temperature, 2-m humidity, and $10-\mathrm{m}$ wind measurements from the West Texas, Oklahoma, Kansas, and Nebraska "mesonets" (S. Benjamin 2019, personal communication; https://madis.ncep.noaa.gov/mesonet_ providers.shtml). An important point to remember is that the LIS offline DA simulation does assimilate all available SMAP soil moisture data on an hourly basis during April-September, beginning from 1 April 2015. Thus, the LIS DA simulation carries forward cumulative memory of all historical SMAP soil moisture updates (Figs. S4-S6 in the online supplemental material).

\section{c. Evaluation method}

The impact of SMAP DA on simulated surface sensible weather, turbulent heat flux partitioning, and PBL winds is quantified both in Eulerian fixed-domain and Lagrangian jetrelative frames of reference. The SCP constitutes the Eulerian domain of analysis, whereas GPLLJ entrance, core, and exit sector locations unique to each jet event constitute the comparison regions in the Lagrangian analysis. Results are presented for the individual jet, 32 coupled jet, 43 uncoupled jet, and 75-jet total event samples to document the range of potential SMAP DA-induced forecast differences as well as to test the hypothesis that SMAP DA effectiveness varies significantly according to jet dynamical class (i.e., coupled or uncoupled). 

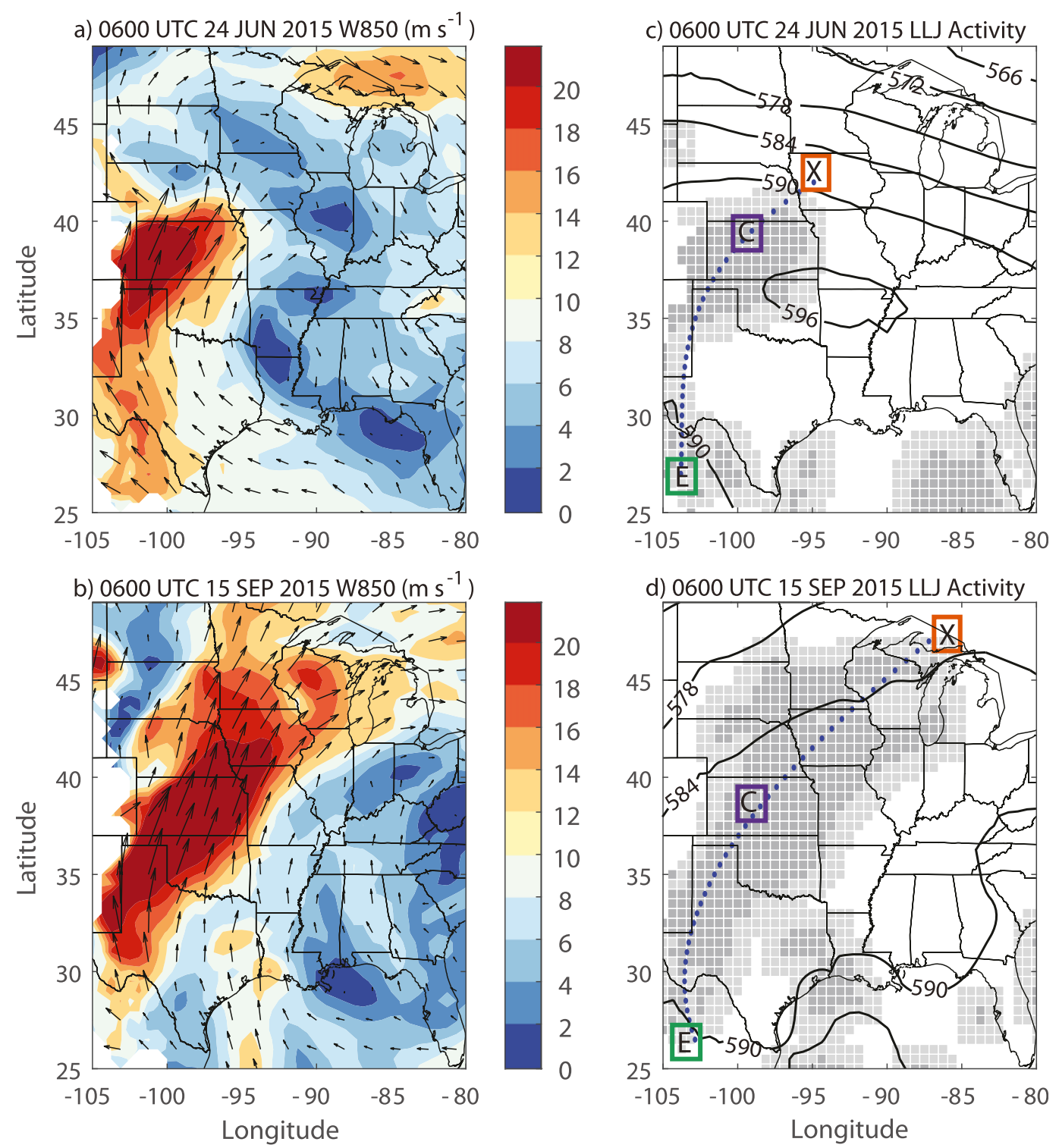

FIG. 2. MERRA-2 0600 UTC 850-hPa wind speed (W850; color map and vectors) during the (a) 24 Jun 2015 uncoupled GPLLJ and (b) 15 Sep 2015 coupled GPLLJ. (c),(d) The corresponding LLJ activity: Z500 contours (dam) overlain on the jet track (dotted blue), corridor (shaded grids), and sector centers (E: entrance; C: core; X: exit). Dark-gray grids satisfy GPLLJ W850 and W850-W700 shear thresholds, whereas light-gray grids mark the extent of the corridor after spatial smoothing.

Analyses span the period from 1900 UTC Day 0 to 1300 UTC Day 1 , following an atmospheric model spinup of $6 \mathrm{~h}$ (i.e., 1300-1900 UTC Day 0). Particular focus is placed on the initial 0-10-cm soil moisture $\left(\mathrm{SM}_{0-10 \mathrm{~cm}}\right)$ differences at 1300 UTC on Day 0, subsequent differences in the 2100 UTC (i.e., 1600 LT) Day 0 surface and PBL environment, and 0900 UTC (i.e., 0400 LT) Day $1 \mathrm{~W} 850$, near the time of maximum GPLLJ speed (e.g., Campbell et al. 2019). Statistics are computed at the $0.08^{\circ} \times 0.08^{\circ}$ grid scale, and the distribution mean and/or full boxplot summary is presented. Three primary statistics are reported: mean difference, mean absolute difference (MAD), and root-mean-square difference (RMSD). MAD is more intuitive than RMSD and less sensitive to outliers given differences are weighted linearly in the estimation of MAD and quadratically in the estimation of RMSD. However, RMSD has a long history of use in forecast verification. Bootstrapping with 1000 or 10000 realizations is used to test for significance at the $\alpha=0.1$ level in the multijet composite and individual jet analyses, respectively. RAP analysis is applied in a limited capacity to evaluate WRF W850 biases. Last, select results from a similar set of WRF simulations with the Mellor-Yamada-Nakanishi-Niino PBL scheme substituted for the Yonsei University PBL scheme are provided in the online supplemental material. In the interest 
a) SMAP Coverage

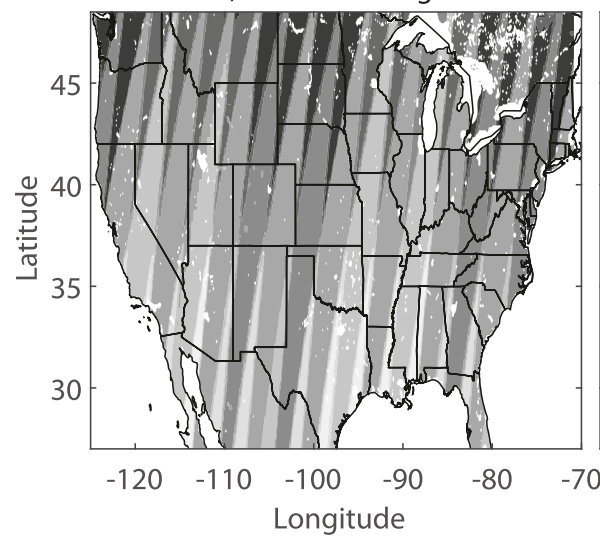

b) Assimilated SMAP L3 Coverage

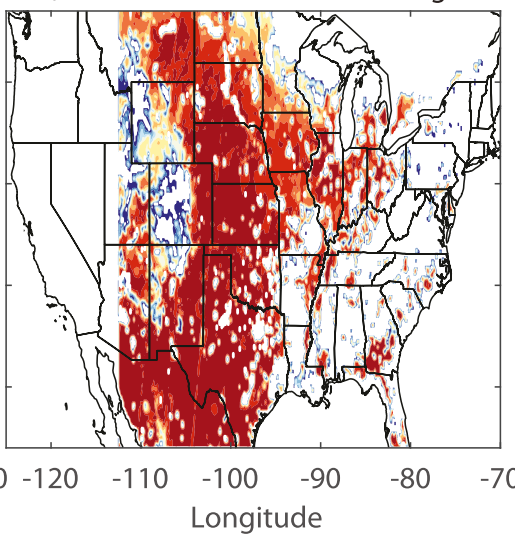

c) $\mathrm{SM}_{0-10 \mathrm{~cm}}$ Update @13UTC

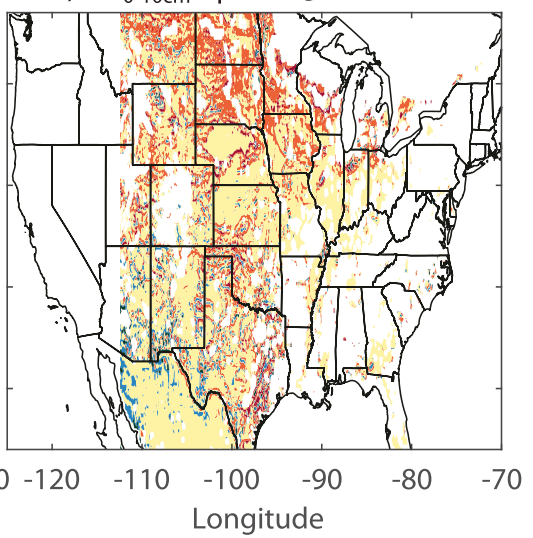

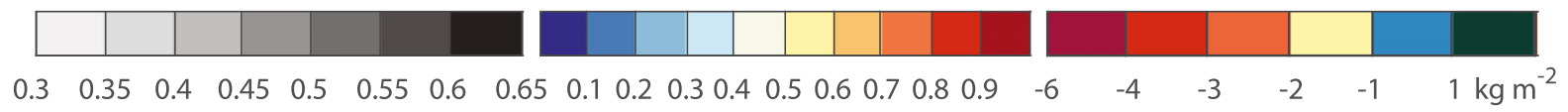

FIG. 3. (a) Fraction of 75-jet sample with morning ( 1228-1305 UTC) SMAP overpass on Day 0 of the event (i.e., the day prior to the targeted jet event). (b) Fraction of SMAP data in (a) that passes observational and model quality screening [see section $2 b(2)]$. (c) The 75-jet mean WRF SMAP-DA update $\left(\mathrm{kg} \mathrm{m}^{-2}\right)$ to $0-10-\mathrm{cm}$ soil moisture $\left(\mathrm{SM}_{0-10 \mathrm{~cm}}\right)$ upon model initialization at $1300 \mathrm{UTC}$ on Day 0. SMAP L3 data west of $112.5^{\circ} \mathrm{W}$ are not available until 1400 UTC because of truncation of overpass time to either 0600 or 1800 local time early in the $\mathrm{L} 3$ production sequence.

of succinctness, they are not discussed because they support the same conclusions.

GPLLJ sectors are defined by a $345-\mathrm{km}$ radius equal to the decorrelation length $s$ of jet entrance and exit sector W850 computed by fitting an exponential function to the scatterplot of correlation coefficients between W850 at two grids and the distance between those grids:

$$
S(d)=e^{-d / s},
$$

where $S$ is Pearson correlation and $d$ is distance between grids (e.g., Rasmussen et al. 2012). Specifically, $s$ is computed using MERRA-2 0600 UTC W850 for all jets greater than $1000 \mathrm{~km}$ in length between April and September 2010-19, which amounts to a sample size of 750 . A much longer decorrelation length $(s=974 \mathrm{~km})$ is found for W850 at the jet core, partly because grids west of the core with surface pressure less than $850 \mathrm{hPa}$ are omitted from the correlation estimate without penalty (Fig. S7 in the online supplemental material).

The jet sector locations for each jet are defined by their MERRA-2 0600 UTC locations. Fixing the sector locations in time and identically for WRF SMAP DA and no-DA simulations simplifies physical interpretation of their differences. Specifically, fixing sector locations controls for the effects of spatial heterogeneities in vegetation and terrain. All jet sectors tend to be well defined at 0600 UTC whereas the entrance sector is not always well-defined at 0900 UTC. Figure 2 presents the results of the automated jet mapping algorithm for representative uncoupled GPLLJ (24 June 2015) and coupled GPLLJ (15 September 2015) events. Additional details about the jet mapping, as well as the climatological mean positioning of jet sectors may be found in the online supplemental material.

\section{Results}

\section{a. Event-averaged results over the modeled domain}

Figure 3 a shows that grids within the WRF simulated domain are overpassed by SMAP on $35 \%-55 \%$ of the 75 -jet-case Day 0s (i.e., the morning prior to the targeted jet). Of the corresponding SMAP L3 soil moisture retrievals over the Great Plains, $80 \%-90 \%$ pass observational and model quality screening [section $2 \mathrm{~b}(2)$ ] and are successfully assimilated at 1300 UTC (Fig. 3b). Retrievals west of $112.5^{\circ} \mathrm{W}$ are not assimilated at 1300 UTC, but they are assimilated at other time steps during April-September in the continuous LIS DA run. Overpass times were truncated to either 0600 or 1800 LT in L3 preprocessing such that retrievals in the Pacific time zone tend to be timestamped 1400 UTC.

Over the full domain the 75 -jet mean $\mathrm{SM}_{0-10 \mathrm{~cm}}$ update is $-1.1 \mathrm{~kg} \mathrm{~m}^{-2}$ and the $5 \%-95 \%$ range is from -5.0 to $+1.7 \mathrm{~kg} \mathrm{~m}^{-2}$ (Fig. 3c). Besides a few grids in Mexico, New Mexico, and Arizona, SMAP DA has the effect of reducing $\mathrm{SM}_{0-10 \mathrm{~cm}}$. The mean updates are nominal in Kansas and southern Nebraska, more substantial in parts of Texas and western Oklahoma, and largest in the northern Great Plains.

Decreases in $\mathrm{SM}_{0-10 \mathrm{~cm}}$ due to SMAP DA tend to enhance 0900 UTC W850 on the subsequent day by $0.25-0.5 \mathrm{~m} \mathrm{~s}^{-1}$, which serves to mitigate an overall negative WRF W850 bias of $1-4 \mathrm{~m} \mathrm{~s}^{-1}$ relative to RAP analysis (Fig. 4). Thus, SMAP DA is improving W850 forecast skill, even if only marginally. The high degree of spatial variability in the sign and magnitude of mean SMAP DA-induced W850 shifts suggests large interevent differences and/or strong correlation with shifts in jet track (e.g., Campbell et al. 2019) and/or convective precipitation patterns (e.g., Frye and Mote 2010). Accordingly, the focus hereinafter is shifted to 


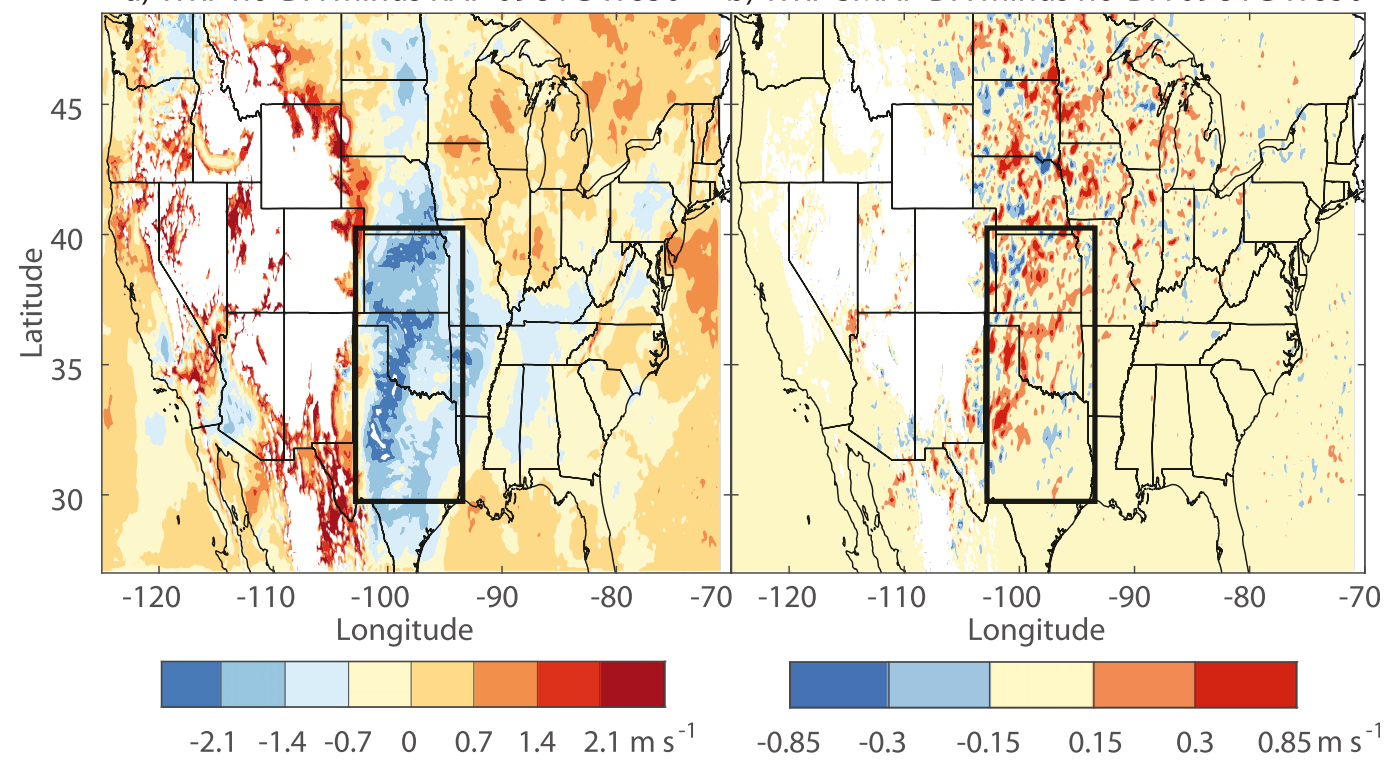

FIG. 4. For the 75-jet sample, the (a) mean WRF no-DA 0900 UTC W850 bias relative to RAP analysis and (b) mean difference in W850 between WRF SMAP DA and no-DA at 0900 UTC. Surface height exceeds the 850 -hPa pressure height in masked-out (white) areas. The rectangular box demarcates the SCP: $29.75^{\circ}-40.25^{\circ} \mathrm{N}$, $\left.102.8125^{\circ}-93.4375^{\circ} \mathrm{W}\right)$.

analyzing WRF SMAP DA and no-DA differences in a jet sector-relative framework.

\section{b. Jet-relative results}

\section{1) JET ENSEMBLE-AVERAGED 1000-500-HPA WIND SPEED DIFFERENCE COMPOSITES}

Figure 5 illustrates that SMAP DA begins to have a significant impact on wind forecasts soon after sunset (0200 UTC) on Day 1 (i.e., $13 \mathrm{~h}$ into the simulation) and the magnitude of the impact enhances through the nighttime hours peaking between 0500 and 0900 UTC — earlier for the jet entrance and later for the jet exit in uncoupled GPLLJs. At the jet core, significant differences between WRF SMAP DA and no-DA mean winds extend up to $550 \mathrm{hPa}$, particularly in the uncoupled GPLLJ sample. Winds at the jet exit are strengthened in the case of uncoupled GPLLJs and weakened in the case of coupled GPLLJs. At the jet entrance, despite substantial SMAP DA soil moisture updates (Fig. 3c), significant wind differences are limited to the lowest levels $(1000-850 \mathrm{hPa})$ between 0600 and 0800 UTC for the uncoupled GPLLJ sample; the impact of SMAP DA on coupled GPLLJ entrance winds is insignificant. One likely explanation is that GPLLJs are strongly influenced by Gulf of Mexico/ocean SST gradients and/or local orographic effects at the entrance region and that soil moisture effects accumulate over time as the jet progresses inland.

Mean absolute WRF SMAP DA and no-DA wind speed differences increase approximately linearly over the course of the simulation with maximum differences vertically at $850 \mathrm{hPa}$ for the jet entrance and core samples around 0600 and 0900 UTC (Figs. 5a-c). At the jet exit, absolute wind speed differences also vary nearly linearly with time, but are more uniform with height, and peak at the end of the simulation (1300 UTC, Day 1; Figs. 5c,f,i). Coupled and uncoupled jet wind field response to SMAP DA differs significantly at most times and pressure levels, and for all jet sectors (Figs. $5 \mathrm{~d}-\mathrm{i}$ ). Only from 0400 to $0800 \mathrm{UTC}$ and between 700 and $875 \mathrm{hPa}$ at the jet core do both jet types respond similarly to SMAP DA (Figs. 6e,h). Overall, average WRF SMAP DA and no-DA wind differences, absolute differences, and root-mean-square differences are significant but relatively modest with $5 \%-95 \%$ ranges of $\pm 0.1 \mathrm{~m} \mathrm{~s}^{-1}$ (Fig. 5), $0-1.3 \mathrm{~m} \mathrm{~s}^{-1}$ (Fig. 6), and $0-2.2 \mathrm{~m} \mathrm{~s}^{-1}$ (Fig. S8 in the online supplemental material), respectively, across all pressure levels. Daytime low-level winds are largely unaffected by SMAP DA despite significant SMAP DA-induced 2-m temperature and humidity differences (shown next). One likely explanation for this finding is that surface frictional effects dominate the low-level wind field up until nocturnal decoupling of the PBL. Only then do SMAP DA-induced regional soil moisture gradient and PBLH differences begin to impact the GPLLJ via their perturbation of the sloped terrain thermal gradient (Holton 1967) and nocturnal inertial oscillation (Blackadar 1957) forcing mechanisms, respectively (e.g., Campbell et al. 2019).

\section{2) DIFFERENCES AT THE LAND-ATMOSPHERE INTERFACE BY JET CASE}

The impact of SMAP DA on simulated sensible weather and PBL winds varies significantly between individual jet cases. Furthermore, WRF SMAP DA and no-DA wind speed differences at a point can be substantial. As shown in Fig. 7 for one representative uncoupled GPLLJ and one representative coupled GPLLJ, the 0900 UTC W850 differences can reach 

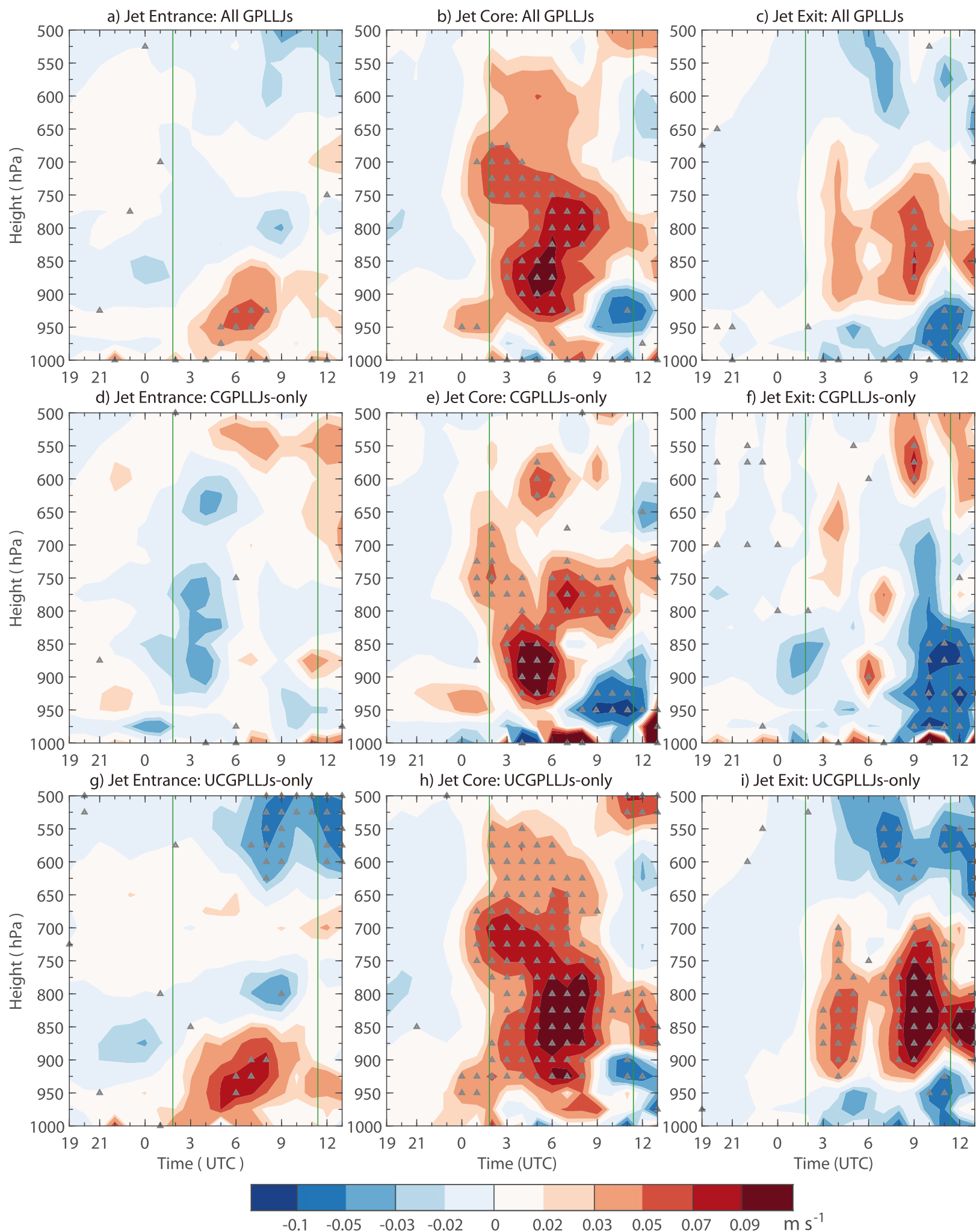

FIG. 5. (a)-(c) The jet sample-mean wind speed difference for SMAP DA minus no-DA WRF ( $\mathrm{m} \mathrm{s}^{-1}$ ) at each 25 -hPa pressure level from 1000 to $500 \mathrm{hPa}$, for each hour from 1900 UTC Day 0 to 1300 UTC Day 1, and for each jet sector. Also shown are similar results for the (d)-(f) coupled GPLLJ and (g)-(i) uncoupled GPLLJ samples. The underlying sample size varies by jet class and sector (see Table 1). Stippling denotes significance of the wind speed differences between WRF SMAP-DA and no-DA at the $\alpha=0.1$ level, computed from 1000 bootstrapped samples. Vertical green lines denote local approximate sunrise (1124 UTC) and sunset (0149 UTC) on 15 Jul at Lamont, Oklahoma $\left(36.6^{\circ} \mathrm{N}, 97.5^{\circ} \mathrm{W}\right)$. Jet entrance, core, and exit locations are fixed over the analysis window to their position at $0600 \mathrm{UTC}$ on Day 1. 

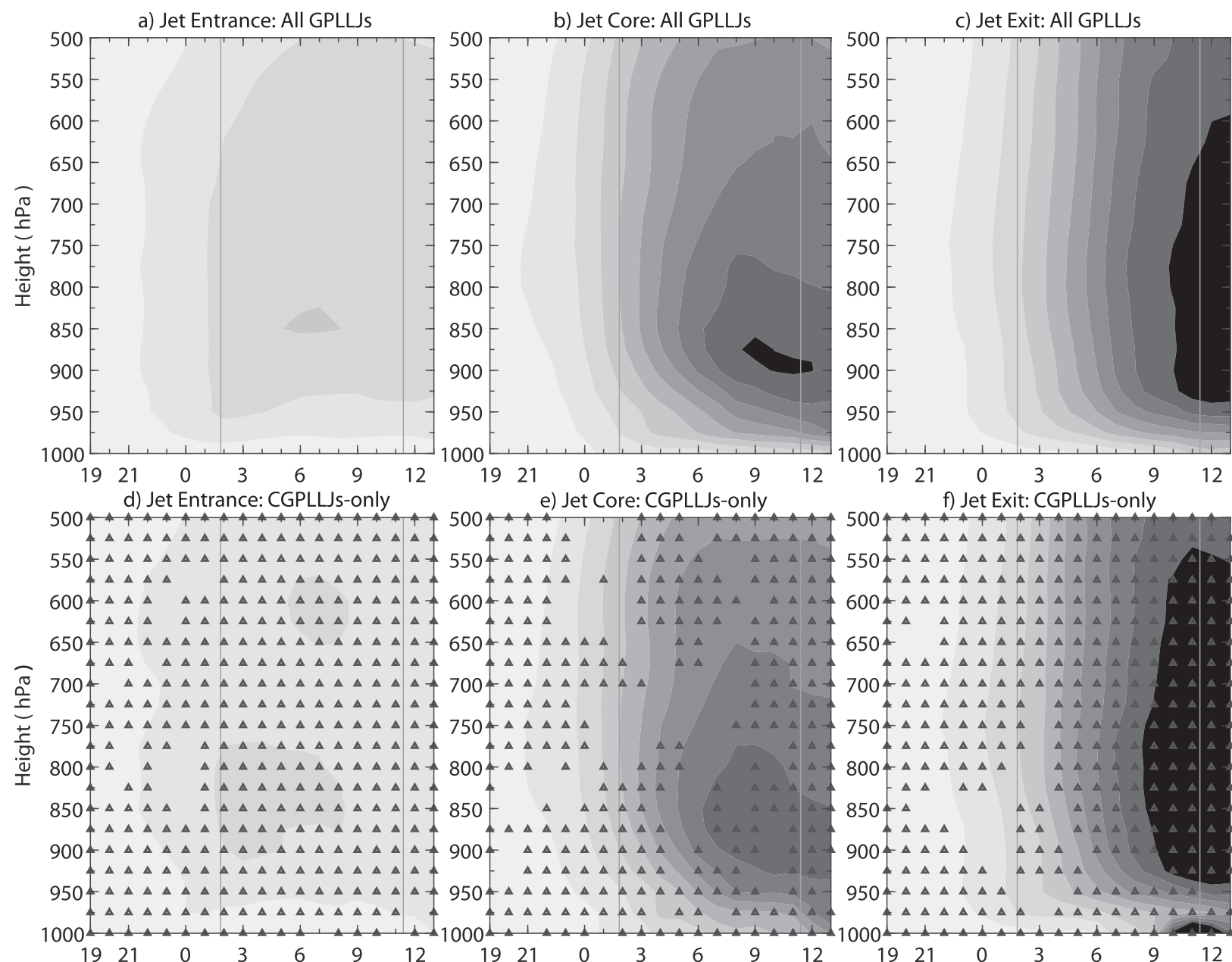

g) Jet Entrance: UCGPLLJs-only
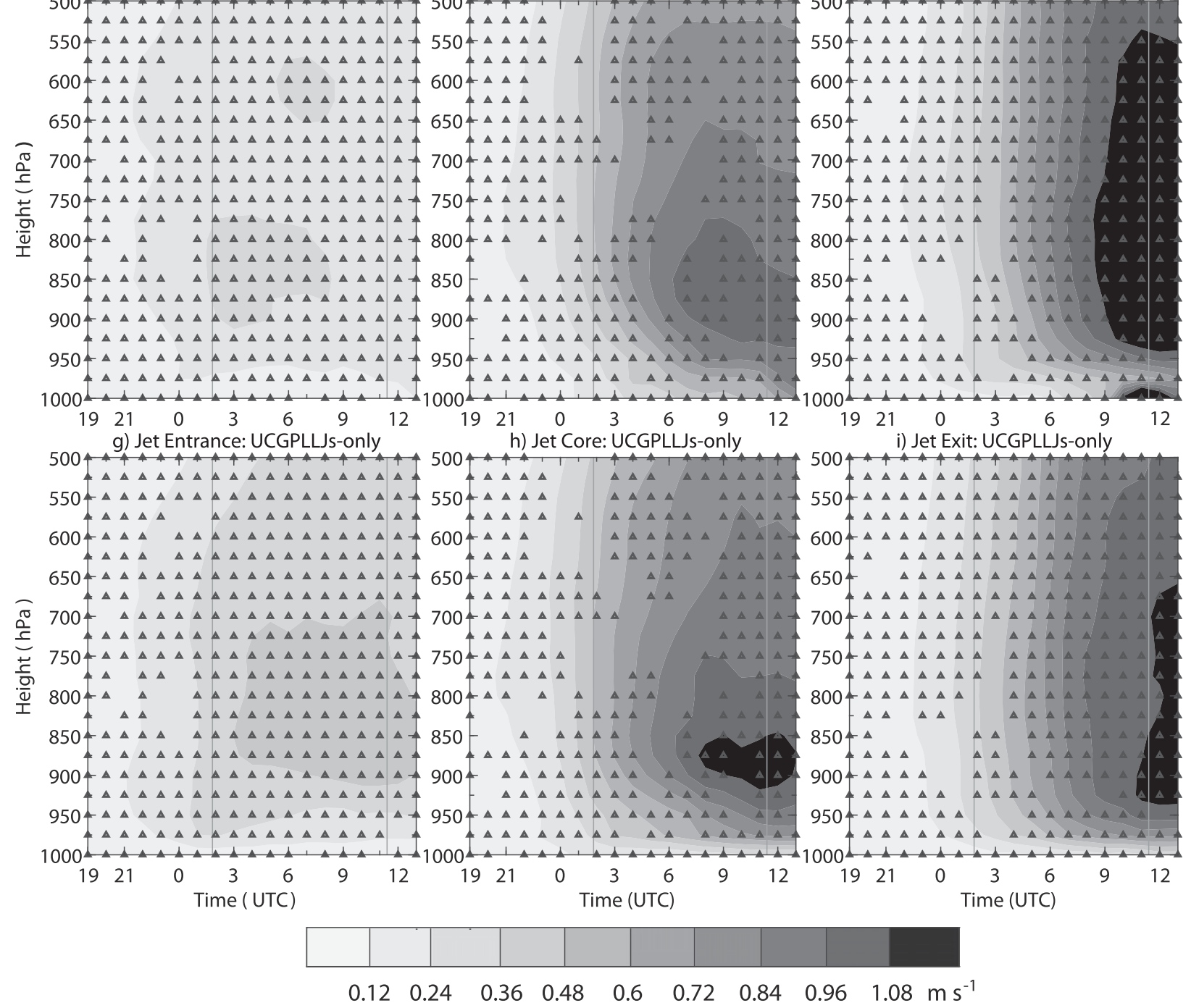

FIG. 6. As in Fig. 5, but for the MAD in wind speed between WRF SMAP DA and no-DA simulations. The stippling in (d)-(i) denotes a significant difference at the $\alpha=0.1$ level between coupled and uncoupled GPLLJ MAD. 


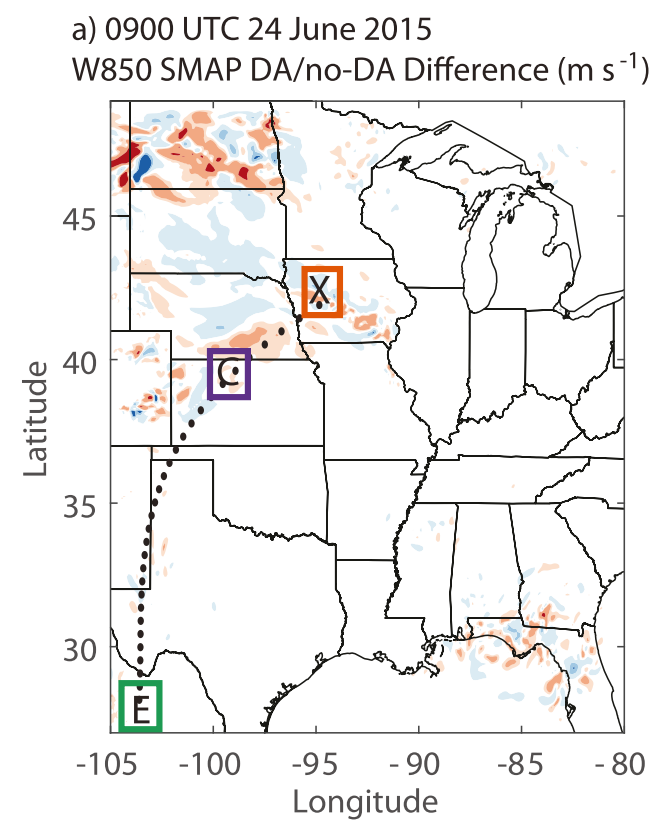

b) 0900 UTC 15 September 2015

W850 SMAP DA/no-DA Difference $\left(\mathrm{m} \mathrm{s}^{-1}\right)$

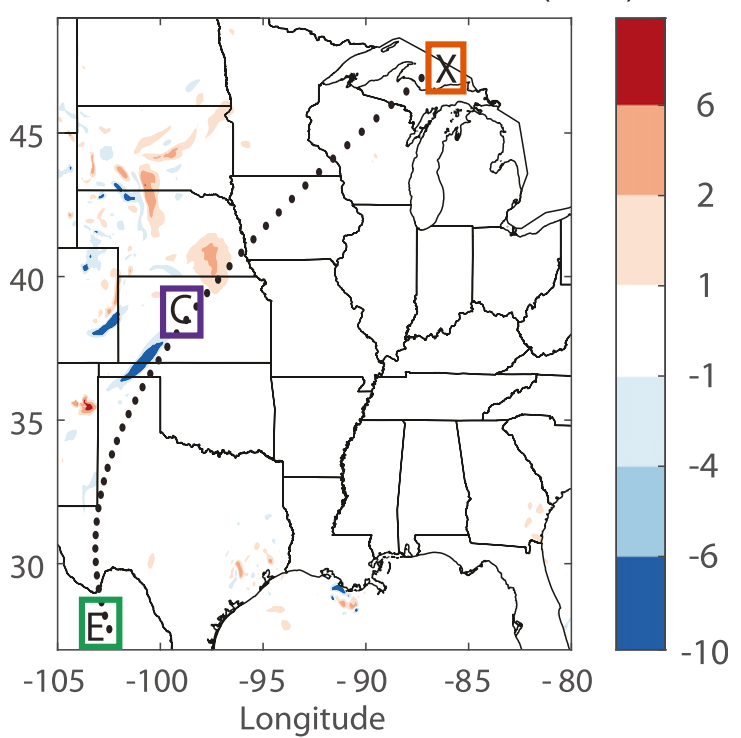

FIG. 7. WRF SMAP DA minus no-DA 0900 UTC W850 for the (a) 24 Jun 2015 uncoupled GPLLJ and (d) 15 Sep 2015 coupled GPLLJ (background W850 is shown in Fig. 2).

upward of $6-10 \mathrm{~m} \mathrm{~s}^{-1}$. In the case of the 24 June 2015 uncoupled GPLLJ, substantial W850 differences are found at the jet core and exit, whereas for the 15 September 2015 coupled GPLLJ W850 differences are clustered near the jet core.

Figure 8 illustrates for each jet, the mean and interquartile range of gridscale WRF SMAP DA and no-DA differences within the jet core for several variables in the land-atmosphere coupling process chain at critical times during the 24-h simulation: $\mathrm{SM}_{0-10 \mathrm{~cm}}$ upon initialization (i.e., 1300 UTC Day 0); 2-m temperature, 2-m specific humidity, surface latent and sensible heat fluxes, and PBLH near the time of maximum PBLH (i.e., 2100 UTC Day 0); and W850 at 0900 UTC Day 1 when the GPLLJ core and exit winds are greatest. The event-scale boxplots are broadly consistent with expected coupled landatmosphere response to changes in surface soil moisture in a semiarid climate: when SMAP DA leads to a reduction in $\mathrm{SM}_{0-}$ $10 \mathrm{~cm}$, afternoon sensible heat flux increases, latent heat flux decreases, 2-m temperature increases, 2-m specific humidity decreases, and PBLH increases (Fig. 8). The linear correlation is significant between the event mean SMAP DA $\mathrm{SM}_{0-10 \mathrm{~cm}}$ update (navy blue line in Fig. 8g) and all variables considered, except 0900 UTC W850 and 0000-1200 UTC precipitation. Derived regression slopes between the SMAP DA SM $S_{0-10 \mathrm{~cm}}$ updates and consequent sensible heat flux, latent heat flux, 2-m specific humidity, and 2-m temperature differences are larger for the coupled GPLLJs, but the difference between coupled and uncoupled GPLLJ derived slopes is only significant for sensible heat flux and 2-m temperature (Table 3). The soil moisture-PBLH regression slope is greater for uncoupled GPLLJs, but not significantly. Correlation coefficients and bivariate regression slopes were similarly computed for the jet entrance and exit sectors and one noteworthy finding is that
SMAP DA SM S-10cm $_{0}$ updates and 0000-1200 UTC precipitation are significantly correlated at the uncoupled GPLLJ entrance and exit (Table S2 in the online supplemental material).

The lack of a significant correlation between the SMAP DA $\mathrm{SM}_{0-10 \mathrm{~cm}}$ update and W850 (for any sector/jet class) and precipitation (for both jet classes at the core and for coupled GPLLJs at the entrance and exit) (Table 3; supplemental Table S2) may be explained by the relatively shorter correlation scale lengths (i.e., higher spatial variability) of W850 and precipitation relative to the other variables investigated. Despite a strong mesoscale correlation between surface soil moisture and PBLH, larger scale synoptic forcing also plays a role in determining the vertical structure and superpositioning of the GPLLJ upon the regional topography (e.g., Burrows et al. 2020, 2019). Topography and, to a lesser extent, vegetation can modify any potential $\mathrm{SM}_{0-10 \mathrm{~cm}^{-}}$ W850 or $\mathrm{SM}_{0-10 \mathrm{~cm}}$-precipitation correlation. A larger jet sample is needed to further probe these causal relationships (e.g., Welty et al. 2020).

\section{3) DIFFERENCES AT THE LAND-ATMOSPHERE INTERFACE BY JET CLASS}

The boxplots in Fig. 9 (and their numerical representation in Table S3 in the online supplemental material) summarize the collective total, uncoupled, and coupled GPLLJ distributions of gridscale WRF SMAP DA and no-DA absolute differences for the same set of land-atmosphere coupling variables analyzed in the previous section. The boxplots are organized by domain: SCP, jet entrance, jet core, and jet exit, and by jet class: total, uncoupled, and coupled GPLLJ. At the jet core, the MADs are $1.1 \mathrm{~m} \mathrm{~s}^{-1}$ (W850), $60 \mathrm{~m}$ (PBLH), $0.21^{\circ} \mathrm{C}(2-\mathrm{m}$ temperature), $0.21 \mathrm{~g} \mathrm{~kg}^{-2}$ (2-m specific humidity), $16.4 \mathrm{~W} \mathrm{~m}^{-2}$ 


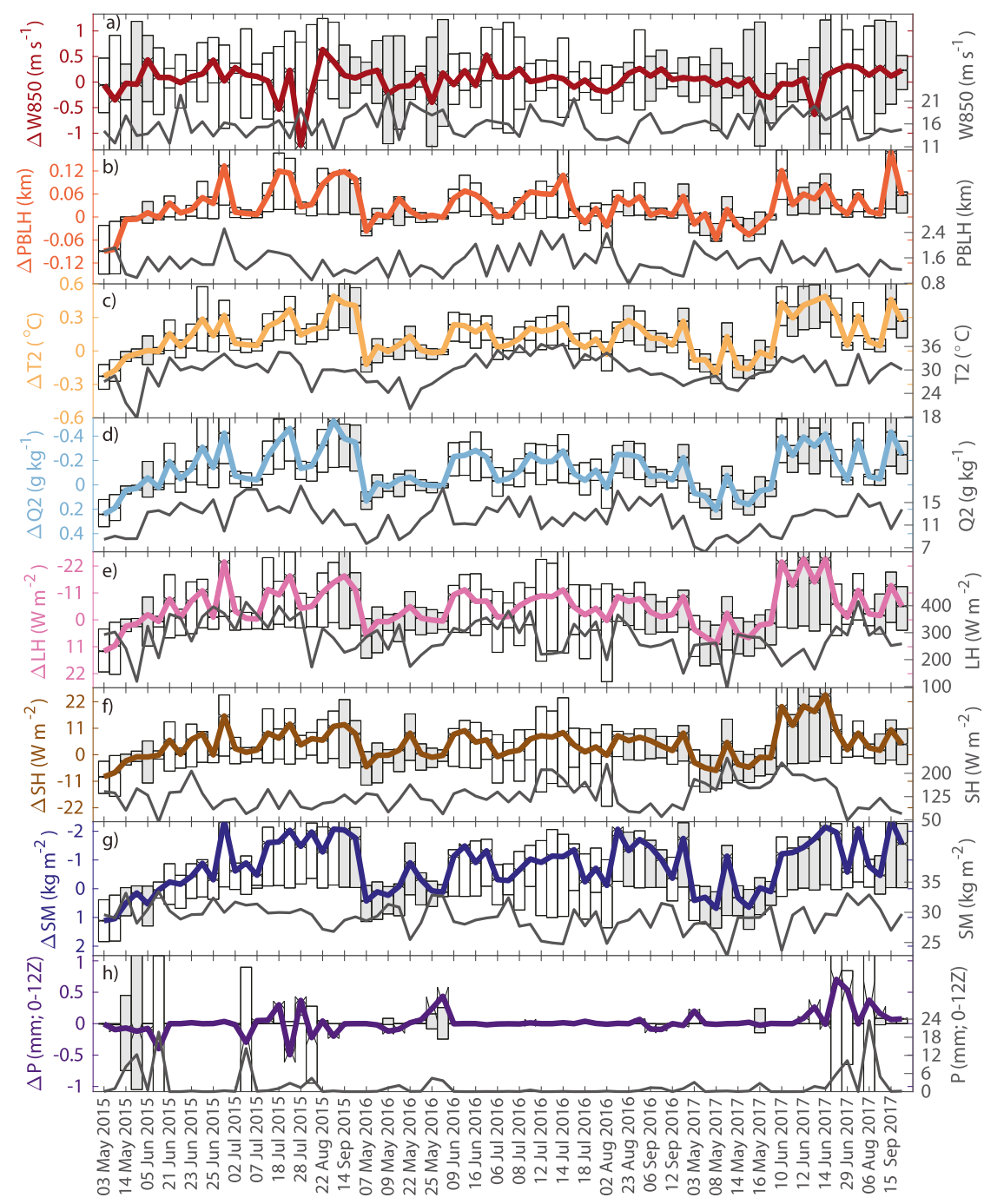

FIG. 8. Event-specific WRF SMAP DA minus no-DA mean differences (colored lines), interquartile range of differences ( $25 \%-75 \%$, bars), and no-DA mean values (black lines) calculated from the sample of all land grids within the jet core sector for which the 850-hPa level lies above the surface. Shown are the (a) 0900 UTC Day 1 W850; 2100 UTC Day 0 (b) planetary boundary layer height (PBLH), (c) 2-m air temperature (T2), (d) 2-m specific humidity (Q2), (e) surface latent heat flux (LH), and (f) surface sensible heat flux (SH); (g) 1300 UTC Day $0 \mathrm{SM}_{0-10 \mathrm{~cm}}$; and (h) 0000-1200 UTC Day 1 accumulated precipitation $P$. The unshaded and shaded bars denote uncoupled GPLLJ and coupled GPLLJ events, respectively. Because of plotting considerations and constraints: the $y$ axes for $\mathrm{SM}_{0-10 \mathrm{~cm}}, \mathrm{LH}$, and Q2 are reversed; some interquartile bars are truncated, and only every other event date is labeled. Note that the events are listed in chronological order from left to right (see Table 1 for a full listing).

(latent heat flux), $14.0 \mathrm{~W} \mathrm{~m}^{-2}$ (sensible heat flux), $1.5 \mathrm{~kg} \mathrm{~m}^{-2}$ $\left(\mathrm{SM}_{0-10 \mathrm{~cm}}\right), 0.8 \mathrm{~mm}$ (precipitation), and $1.4 \mathrm{~m} \mathrm{~s}^{-1}$ (W850W700 shear; Table S3) (Table 4). The corresponding 95\% absolute differences are $4.0 \mathrm{~m} \mathrm{~s}^{-1}$ (W850), $240 \mathrm{~m}$ (PBLH), $0.68^{\circ} \mathrm{C}$ (2-m temperature), $0.71 \mathrm{~g} \mathrm{~kg}^{-2}$ (2-m specific humidity), $59.9 \mathrm{~W} \mathrm{~m}^{-2}$ (latent heat flux), $52.4 \mathrm{~W} \mathrm{~m}^{-2}$ (sensible heat flux), $5.4 \mathrm{~kg} \mathrm{~m}^{-2}\left(\mathrm{SM}_{0-10 \mathrm{~cm}}\right), 4.3 \mathrm{~mm}$ (precipitation), and $5.3 \mathrm{~m} \mathrm{~s}^{-1}$ (W850-W700 shear) (Table S3). Corresponding RMSD values are also provided in Table 4.
A few key takeaways from Fig. 9 are worth noting. First, SCP mean absolute WRF SMAP DA and no-DA differences in $\mathrm{SM}_{0-10 \mathrm{~cm}}$, and all response variables except precipitation, are largest for the uncoupled GPLLJ sample. For example, uncoupled GPLLJ mean absolute PBLH differences are $52 \mathrm{~m}$, as compared with $45 \mathrm{~m}$ for coupled GPLLJs. Considering that large-scale frontal precipitation associated with coupled GPLLJs makes these events wetter on average to begin with (e.g., Burrows et al. 2019), it is not surprising that SMAP 
TABLE 3. GPLLJ event jet core areal mean WRF SMAP DA minus no-DA difference for each variable of interest ( $y$; colored lines in Fig. 8) regressed against the event jet core areal mean WRF SMAP DA minus no-DA difference in $1300 \mathrm{UTC}$ Day $0 \mathrm{SM}_{0-10 \mathrm{~cm}}(x)$. As in Fig. 8, only land grids within the jet core sector for which the $850-\mathrm{hPa}$ level lies above the surface are included in the calculation. The regression slopes $[m$ in $E(y)=m x+b]$ are based on $74 / 75$ jets (the 23 Sep 2016 jet core is out of bounds). All correlation coefficients are significant at the $\alpha=0.1$ level, except for those between $\mathrm{SM}_{0-10 \mathrm{~cm}}$ and $\mathrm{W} 850$ and $P$ (italicized). Boldfaced values are significantly different at the $\alpha=0.1$ level between coupled and uncoupled GPLLJ samples.

\begin{tabular}{|c|c|c|c|c|c|c|c|c|}
\hline \multirow[b]{2}{*}{ Valid time } & \multirow[b]{2}{*}{$\begin{array}{c}\text { Variable } \\
\text { (units) }\end{array}$} & \multicolumn{3}{|c|}{ Pearson's $r$} & \multicolumn{4}{|c|}{ Regression slope } \\
\hline & & $\begin{array}{l}\text { C GPLLJs } \\
\text { only }\end{array}$ & $\begin{array}{l}\text { UC GPLLJs } \\
\text { only }\end{array}$ & $\begin{array}{c}\text { All } \\
\text { GPLLJs }\end{array}$ & $\begin{array}{l}\text { C GPLLJs } \\
\text { only }\end{array}$ & $\begin{array}{l}\text { UC GPLLJs } \\
\text { only }\end{array}$ & $\begin{array}{c}\text { All } \\
\text { GPLLJs }\end{array}$ & Units \\
\hline \multirow[t]{5}{*}{2100 UTC Day 0} & $\mathrm{SH}\left(\mathrm{W} \mathrm{m}^{-2}\right)$ & -0.87 & -0.83 & -0.85 & -7.03 & -5.68 & -6.27 & $\mathrm{~W} \mathrm{~kg}^{-1}$ \\
\hline & $\mathrm{LH}\left(\mathrm{W} \mathrm{m}^{-2}\right)$ & 0.86 & 0.81 & 0.84 & 8.05 & 7.25 & 7.66 & $\mathrm{~W} \mathrm{~kg}^{-1}$ \\
\hline & Q2 $\left(\mathrm{g} \mathrm{kg}^{-1}\right)$ & 0.92 & 0.84 & 0.89 & 0.176 & 0.168 & 0.174 & $\mathrm{~g} \mathrm{~m}^{2} \mathrm{~kg}^{-2}$ \\
\hline & $\mathrm{T} 2(\mathrm{~K})$ & -0.94 & -0.86 & -0.90 & -0.202 & -0.154 & -0.176 & $\mathrm{~K} \mathrm{~m}^{2} \mathrm{~kg}^{-1}$ \\
\hline & PBLH (m) & -0.84 & -0.80 & -0.82 & -42.0 & -47.7 & -44.8 & $\mathrm{~m}^{3} \mathrm{~kg}^{-1}$ \\
\hline 0900 UTC Day 1 & $\mathrm{~W} 850\left(\mathrm{~m} \mathrm{~s}^{-1}\right)$ & -0.08 & -0.07 & -0.08 & -0.019 & -0.026 & -0.025 & $\mathrm{~m}^{3} \mathrm{~kg}^{-1} \mathrm{~s}^{-1}$ \\
\hline $\begin{array}{l}\text { 0000-1200 UTC } \\
\text { Day } 1\end{array}$ & $P(\mathrm{~mm})$ & -0.09 & -0.05 & -0.06 & -0.011 & -0.013 & -0.011 & - \\
\hline
\end{tabular}

DA-induced differences in precipitation are larger for coupled GPLLJs. Second, PBLH MADs are larger at the jet entrance (all jets: $60 \mathrm{~m}$ ) and core (all jets: $64 \mathrm{~m}$ ) than at the jet exit (all jets: $27 \mathrm{~m}$ ). Third, W850 MADs are largest at the jet core and exit and smallest at the jet entrance (all jets: mean $=$ $0.35 \mathrm{~m} \mathrm{~s}^{-1} ; \mathrm{p} 95=1.4 \mathrm{~m} \mathrm{~s}^{-1}$ ). Fourth, mean absolute W850 differences are significantly larger for uncoupled GPLLJs at the entrance (uncoupled GPLLJ mean $=0.43 \mathrm{~m} \mathrm{~s}^{-1}$; coupled GPLLJ mean $\left.=0.23 \mathrm{~m} \mathrm{~s}^{-1}\right)$ but significantly larger for coupled GPLLJs at the exit (coupled GPLLJ mean $=1.12 \mathrm{~m} \mathrm{~s}^{-1}$; uncoupled GPLLJ mean $=1.01 \mathrm{~m} \mathrm{~s}^{-1}$ ). Last, even though MADs tend to be greater for uncoupled GPLLJs, sensitivity to SMAP DA within the jet corridor is higher for certain variables such as sensible heat flux and 2-m temperature during coupled GPLLJs (Table 3). In this instance, the linear sensitivity estimate appears to be skewed by the 12-14 June 2017 coupled GPLLJs for which there was both a large $\mathrm{SM}_{0-10 \mathrm{~cm}}$ reduction and large correspondent increase in sensible heat flux due to SMAP DA (Fig. 8).

The $5 \%-95 \%$ ranges of 0900 UTC W850 absolute differences observed for the uncoupled GPLLJ core and exit (0$4.1 \mathrm{~m} \mathrm{~s}^{-1}$; Table S3 in the online supplemental material) are consistent with the range of $1-4 \mathrm{~m} \mathrm{~s}^{-1}$ previously obtained by Campbell et al. (2019) through an idealized uncoupled GPLLJ sensitivity experiment in which CONUS-wide extreme wet (i.e., 95th percentile) and dry (i.e., 5th percentile) soil moisture scenarios were compared for a single jet case. The fact that our W850 differences fall in line with Campbell et al. (2019) is intriguing because that study reported much larger 2100 UTC PBLH $(700 \mathrm{~m})$ and surface sensible and latent heat $\left(125 \mathrm{~W} \mathrm{~m}^{-2}\right)$ differences. Additional investigation, beyond the scope of this study, is needed to test the hypothesis that large-scale forcing specific to the jet case selected by Campbell et al. (2019) limited the extent of land-forced variability.

\section{c. Emergent relationships between SMAP DA-induced W850 differences and the background environment}

The last set of analyses to be discussed are designed to reduce the large and complex set of modeling results- to the extent possible-into broad, generalizable relationships between jet classes, the surface and atmospheric environments in which they tend to act and interact, and the magnitude of WRF SMAP DA and no-DA 0900 UTC W850 differences. Uncoupled and coupled GPLLJs have important differences in terms of their seasonality, speed, northern extent, and geographic coverage. Coupled GPLLJs are more prevalent in May and September whereas uncoupled GPLLJs are more prevalent in June-August. Coupled GPLLJs tend to be faster, especially over elevated terrain (Fig. 10a), and penetrate farther northand eastward by $2.4^{\circ}$ and $0.4^{\circ}$ (Table 5).

Table 6 summarizes mean differences in elevation, PBLH, and antecedent soil moisture (1300 UTC Day $0 \mathrm{SM}_{0-10 \mathrm{~cm}}$ ) between regions traversed by the 43 uncoupled and 32 coupled GPLLJs. Mean surface elevation decreases for both jet classes from jet entrance $(873 \mathrm{~m})$ to core $(675 \mathrm{~m})$ to exit $(465 \mathrm{~m})$. Only at the jet exit is there a significant difference $(59 \mathrm{~m})$ in mean elevation between jet classes, with coupled GPLLJs terminating over slightly more elevated terrain. PBLH decreases with elevation along the jet track; total jet sample mean PBLH is 2021, 1467, and $1219 \mathrm{~m}$ at jet entrance, core, and exit, respectively. Mean PBLH for uncoupled GPLLJs is $54-56 \mathrm{~m}$ higher than for coupled GPLLJs at jet entrance and exit, and $232 \mathrm{~m}$ higher at jet core. To first order, greater daytime PBLH correlates with faster jet winds after frictional decoupling at night (Blackadar 1957), which together with our finding that SMAP DA decreases jet exit winds for coupled GPLLJs and increases them for uncoupled GPLLJs, further supports the conclusion that SMAP DA tends to spatially extend uncoupled GPLLJs and shorten coupled GPLLJs.

As elevation decreases along the jet track, antecedent $\mathrm{SM}_{0-}$ $10 \mathrm{~cm}$ increases (Fig. 10a). For the full jet sample, mean $\mathrm{SM}_{0-10 \mathrm{~cm}}$ increases from $26.9 \mathrm{~kg} \mathrm{~m}^{-2}$ at the jet entrance to $29.3 \mathrm{~kg} \mathrm{~m}^{-2}$ at the core to $30.5 \mathrm{~kg} \mathrm{~m}^{-2}$ at the exit (Table 6). A counterintuitive result, given that uncoupled GPLLJs occur under conditions of surface drying (e.g., Burrows et al. 2020), is that uncoupled GPLLJ antecedent $\mathrm{SM}_{0-10 \mathrm{~cm}}$ significantly exceeds that of coupled GPLLJ at the jet entrance by a small margin and at the exit by a larger margin (uncoupled GPLLJ: $31.0 \mathrm{~kg} \mathrm{~m}^{-2}$; 


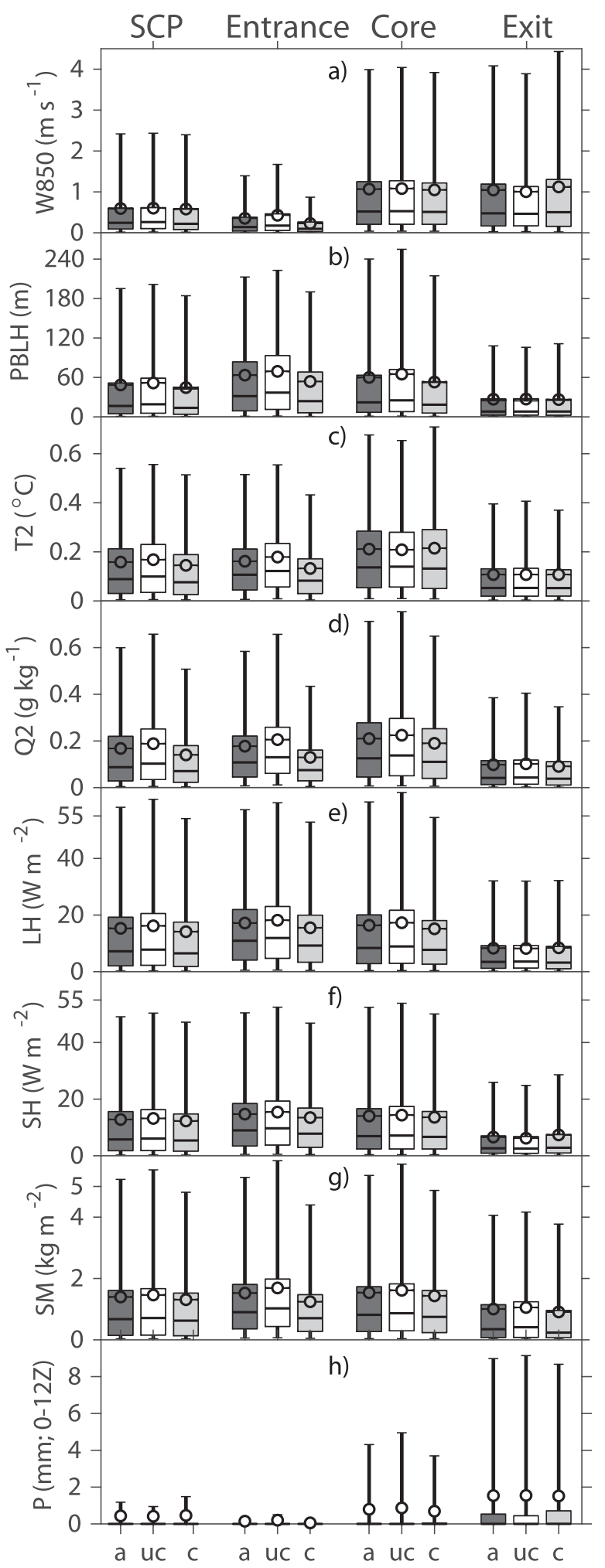

FIG. 9. Boxplots of the distribution of absolute differences between WRF SMAP DA and no-DA simulations of (a) 0900 UTC Day 1 W850; 2100 UTC Day 0 (b) PBLH, (c) T2, (d) Q2, (e) LH, and (f) SH; (g) 1300 UTC Day $0 \mathrm{SM}_{0-10 \mathrm{~cm}}$; and (h) 0000-1200 UTC Day 1 accumulated $P$. From left to right, the groups of boxplots coupled GPLLJ: $29.6 \mathrm{~kg} \mathrm{~m}^{-2}$ ). Upon closer inspection, it was determined that this result may be partly explained by sampling bias. This study's uncoupled GPLLJ sample is heavily weighted toward $2015(n=19)$ and $2016(n=18)$, which constitute the SCP's third and sixth wettest years on record between 1980 and 2019 (Fig. S12 in the online supplemental material). Simultaneously, the coupled GPLLJ comprises very few events in $2015(n=5)$ and many events in $2017(n=$ 14) when the typical exit sector/northern Great Plains was between moderate and severe drought (Blunden 2017). Readers should take this sampling bias into consideration when interpreting the coupled versus uncoupled GPLLJ differences that are reported here, particularly for the exit sector.

Figures 10a and 10b shows that WRF W850 and WRF SMAP DA and no-DA W850 absolute differences both increase with elevation up to approximately $890 \mathrm{~m}$ MSL at a rate of approximately 1.1 and $0.088 \mathrm{~m} \mathrm{~s}^{-1}$ per $100 \mathrm{~m}$ of elevation gain, respectively. Coupled GPLLJs are significantly faster than uncoupled GPLLJs (Fig. 10a), consistent with the findings of Burrows et al. (2020). For the 800-890-m elevation bin specifically, coupled GPLLJ W850 averages $17.7 \mathrm{~m} \mathrm{~s}^{-1}$, which is $2.3 \mathrm{~m} \mathrm{~s}^{-1}$ faster than uncoupled GPLLJ W850. Despite being faster, coupled GPLLJ winds tends to be less impacted by SMAP DA. While it is true that coupled GPLLJ W850 is more sensitive to elevation in comparison to uncoupled GPLLJ W850 (Fig. 10a), it is less sensitive to SMAP DA updates as a function of elevation (Fig. 10b).

Figure 10c shows the mean WRF SMAP DA and no-DA W850 differences partitioned by $\mathrm{SM}_{0-10 \mathrm{~cm}}$. The largest SMAP DA-induced differences are observed in the driest decile (5$15 \mathrm{~kg} \mathrm{~m}^{-2}$ ) and 44th-88th percentile range $\left(30-35 \mathrm{~kg} \mathrm{~m}^{-2}\right)$ of $\mathrm{SM}_{0-10 \mathrm{~cm}}$. Aided by findings from our preceding lines of inquiry, two summary statements may now be made. First, W850 differences due to SMAP DA are larger for uncoupled GPLLJs (Table 4) while at the same time, W850 differences are more strongly correlated with SMAP DA SM $\mathrm{SM}_{0-10 \mathrm{~cm}}$ updates for coupled GPLLJs (Table 3). The relatively lower spatial heterogeneity of $\mathrm{SM}_{0-10 \mathrm{~cm}}$ during coupled GPLLJs as compared to uncoupled GPLLJs may partly explain this finding (not shown). Second, SMAP DA generally has the effect of increasing W850 for uncoupled GPLLJs, whereas it can reduce W850 in some $\mathrm{SM}_{0-10 \mathrm{~cm}}$ and elevation bins for coupled GPLLJs (Figs. 10b,c). For both jet types, SMAP DA leads to increases in W850 at the low end of the wind speed distribution (i.e., W850 $<9 \mathrm{~m} \mathrm{~s}^{-1}$ ) and decreases at the high end of the wind speed distribution (i.e., W850 $>18.5 \mathrm{~m} \mathrm{~s}^{-1}$; Fig. 10d). These observed patterns in W850 changes are consistent with spatial shifts in the jet's axis (i.e., track of

correspond to the SCP, jet entrance, jet core, and jet exit. Darkgray, white, and light-gray boxplots correspond to underlying samples of all (label a), uncoupled-only (label uc), and coupledonly (label c) GPLLJs. A horizontal line within the interquartile range denotes the median, open circles denote the mean, and boxplot whiskers extend from $5 \%$ to $95 \%$. Only land grids for which the $850-\mathrm{hPa}$ level lies above the surface are included. See online supplemental Table S3 for the underlying numerical data. 
TABLE 4. Mean of the absolute differences (Fig. 9; supplemental Table S3) (top half of table) and RMSD of WRF SMAP DA and noDA estimates (bottom half of table) for land-atmosphere variables of interest, computed from the coupled GPLLJ (C), uncoupled GPLLJ (UC), and combined (A) jet samples over the SCP $(n=75)$ and GPLLJ entrance, core, and exit sectors (see Table 1 for sample sizes).

\begin{tabular}{|c|c|c|c|c|c|c|c|c|c|c|c|c|c|}
\hline \multirow[b]{2}{*}{ Valid time } & \multirow[b]{2}{*}{ Variable (units) } & \multicolumn{3}{|c|}{ SCP } & \multicolumn{3}{|c|}{ GPLLJ entrance } & \multicolumn{3}{|c|}{ GPLLJ core } & \multicolumn{3}{|c|}{ GPLLJ exit } \\
\hline & & $\mathrm{C}$ & $\mathrm{UC}$ & A & $\mathrm{C}$ & $\mathrm{UC}$ & A & $\mathrm{C}$ & $\mathrm{UC}$ & A & $\mathrm{C}$ & $\mathrm{UC}$ & A \\
\hline \multicolumn{14}{|c|}{ Mean of WRF SMAP DA and no-DA absolute differences } \\
\hline 1300 UTC Day 0 & $\mathrm{SM}\left(\mathrm{kg} \mathrm{m}^{-2}\right)$ & 1.3 & 1.5 & 1.4 & 1.2 & 1.7 & 1.5 & 1.4 & 1.6 & 1.5 & 0.9 & 1.1 & 1.0 \\
\hline \multirow[t]{5}{*}{2100 UTC Day 0} & $\mathrm{SH}\left(\mathrm{W} \mathrm{m}^{-2}\right)$ & 12 & 13 & 13 & 14 & 15 & 15 & 14 & 14 & 14 & 7 & 6 & 7 \\
\hline & $\mathrm{LH}\left(\mathrm{W} \mathrm{m}^{-2}\right)$ & 14 & 16 & 15 & 16 & 18 & 17 & 15 & 17 & 16 & 8 & 8 & 8 \\
\hline & Q2 $\left(\mathrm{g} \mathrm{kg}^{-1}\right)$ & 0.14 & 0.19 & 0.17 & 0.13 & 0.21 & 0.18 & 0.19 & 0.22 & 0.21 & 0.09 & 0.10 & 0.10 \\
\hline & $\mathrm{T} 2\left({ }^{\circ} \mathrm{C}\right)$ & 0.15 & 0.17 & 0.16 & 0.13 & 0.18 & 0.16 & 0.21 & 0.21 & 0.21 & 0.11 & 0.11 & 0.11 \\
\hline & PBLH (m) & 45 & 52 & 49 & 54 & 69 & 64 & 53 & 65 & 60 & 26 & 27 & 27 \\
\hline 0900 UTC Day 1 & $\mathrm{~W} 850\left(\mathrm{~m} \mathrm{~s}^{-1}\right)$ & 0.58 & 0.60 & 0.59 & 0.23 & 0.43 & 0.35 & 1.05 & 1.08 & 1.07 & 1.12 & 1.01 & 1.05 \\
\hline 0000-1200 UTC Day 1 & $P(\mathrm{~mm})$ & 0.5 & 0.4 & 0.4 & 0.1 & 0.2 & 0.2 & 0.7 & 0.9 & 0.8 & 1.5 & 1.6 & 1.5 \\
\hline \multicolumn{14}{|c|}{ WRF SMAP DA and no-DA root-mean-square differences } \\
\hline 1300 UTC Day 0 & $\mathrm{SM}\left(\mathrm{kg} \mathrm{m}^{-2}\right)$ & 2.6 & 2.8 & 2.7 & 2.1 & 2.8 & 2.6 & 2.8 & 3.0 & 2.9 & 2.1 & 2.1 & 2.1 \\
\hline \multirow[t]{5}{*}{2100 UTC Day 0} & $\mathrm{SH}\left(\mathrm{W} \mathrm{m}^{-2}\right)$ & 23 & 23 & 23 & 22 & 24 & 23 & 25 & 25 & 25 & 16 & 12 & 14 \\
\hline & $\mathrm{LH}\left(\mathrm{W} \mathrm{m}^{-2}\right)$ & 25 & 28 & 27 & 25 & 28 & 27 & 27 & 30 & 29 & 18 & 16 & 17 \\
\hline & Q2 $\left(\mathrm{g} \mathrm{kg}^{-1}\right)$ & 0.24 & 0.31 & 0.28 & 0.22 & 0.32 & 0.29 & 0.30 & 0.35 & 0.33 & 0.17 & 0.20 & 0.19 \\
\hline & $\mathrm{T} 2\left({ }^{\circ} \mathrm{C}\right)$ & 0.24 & 0.26 & 0.25 & 0.21 & 0.26 & 0.24 & 0.32 & 0.31 & 0.31 & 0.20 & 0.18 & 0.19 \\
\hline & PBLH (m) & 113 & 110 & 111 & 105 & 126 & 118 & 124 & 136 & 131 & 67 & 78 & 74 \\
\hline 0900 UTC Day 1 & $\mathrm{~W} 850\left(\mathrm{~m} \mathrm{~s}^{-1}\right)$ & 1.26 & 1.23 & 1.24 & 0.46 & 0.91 & 0.77 & 1.88 & 1.90 & 1.89 & 2.06 & 1.89 & 1.95 \\
\hline 0000-1200 UTC Day 1 & $P(\mathrm{~mm})$ & 3.1 & 3.0 & 3.0 & 1.3 & 1.6 & 1.5 & 3.1 & 4.0 & 3.7 & 4.7 & 5.2 & 5.1 \\
\hline Sample size & $\times 10^{4}$ & 47.0 & 65.2 & 112.2 & 5.3 & 8.9 & 14.2 & 18.5 & 25.4 & 44.0 & 11.0 & 20.8 & 31.8 \\
\hline
\end{tabular}

maximum wind speed), including extension or shortening of the jet's northern exit sector.

A more comprehensive understanding of SMAP DA related W850 differences as a function of W850 magnitude (Fig. 10d) is achieved by partitioning their joint distribution by antecedent $\mathrm{SM}_{0-10 \mathrm{~cm}}$, elevation, and land-cover class. Figure 11a shows that W850 differences are largest in all wind magnitude bins over relatively wet soils (Q3: $\left.32-35 \mathrm{~kg} \mathrm{~m}^{-2}\right)$ and smallest over the driest soils (Q1: $\mathrm{SM}_{0-10 \mathrm{~cm}}<27 \mathrm{~kg} \mathrm{~m}^{-2}$ ). This result is consistent with our findings of lower $\mathrm{SM}_{0-10 \mathrm{~cm}}$ and relatively weaker corresponding SMAP DA effects at the jet entrance (Figs. 5, 6, 9; Table 4). Recall that soil residual water content, which serves as a hard lower bound, may also limit SMAP DA's efficacy at low $\mathrm{SM}_{0-10 \mathrm{~cm}}$.

Figure 11b shows that SMAP DA-induced W850 differences are directly proportional to elevation where W850 is less than $20 \mathrm{~m} \mathrm{~s}^{-1}$, consistent with Fig. 10b. Extreme winds in the WRF simulation are predominantly modified by SMAP DA in lowlying areas (i.e., $<256 \mathrm{~m} \mathrm{MSL}$ ), which tend to align with the jet exit sector (Table 6). This finding supports again the conclusion that SMAP DA plays a significant role in shifting jet exit placement for both jet classes.

Figure 11c reveals that W850 simulations are most affected over crops and grassland land-cover classes for wind speeds below $20 \mathrm{~m} \mathrm{~s}^{-1}$. At extreme winds, large W850 differences tend to occur over pasture/hay, evergreen needleleaf forest, and deciduous forest. Geographically, this places differences in severe winds to the east and north (pasture/hay: Missouri and eastern Kansas; forests: western Arkansas and western Louisiana), near the exit sector of a few sampled jets, and differences in less severe winds over the Texas panhandle and Oklahoma and Kansas grasslands, coincident with mean jet core placement (Fig. 1 and Fig. S3 in the online supplemental material).

\section{Summary and conclusions}

Incremental forecast improvements attributable to SMAP DA are significant at the $\alpha=0.1$ level but are only marginal on time- and area-averaged scales (e.g., Fig. 4b). New insight into the added value of SMAP DA can be gleaned by investigating its forecast contribution within the object-based reference frame of events of opportunity like GPLLJs, as shown here. As we show, SMAP DA can induce changes of up to $4.0 \mathrm{~m} \mathrm{~s}^{-1}$ in simulated W850, particularly within jet core and exit sectors (Figs. 5, 9; Table S3 in the online supplemental material). The W850 changes are the product of the local daytime soil moisture-Bowen ratioPBLH land-atmosphere coupling process chain (e.g., Santanello et al. 2018) and the cumulative effect of its constituent process interactions on the regional Blackadar (1957) and Holton (1967) forcing mechanisms, in a given synoptic environment.

Within the jet core, corrections of up to $5.4 \mathrm{~kg} \mathrm{~m}^{-2}$ in $\mathrm{SM}_{0-10 \mathrm{~cm}}$ can result in 2-m air temperature, 2-m specific humidity, latent heat flux, sensible heat flux, and PBLH differences of $0.68^{\circ} \mathrm{C}, 0.71 \mathrm{~g} \mathrm{~kg}^{-2}, 59.9 \mathrm{~W} \mathrm{~m}^{-2}, 52.4 \mathrm{~W} \mathrm{~m}^{-2}$, and $240 \mathrm{~m}$, respectively (Fig. 9, supplemental Table S3). For example, the jet core PBLH has a linear correlation of -0.82 and regression slope of $-44.8 \mathrm{~m}^{3} \mathrm{~kg}^{-1}$ with $\mathrm{SM}_{0-10 \mathrm{~cm}}$ (Table 3) - both statistically significant. Differences in W850 tend to increase with surface elevation or along the jet axis from south to north (Fig. 10), and maximize within the SCP where $\mathrm{SM}_{0-10 \mathrm{~cm}}$ is in its third quartile (Fig. 11). Over the same regions, soil moisture tends to have higher temporal variability, which increases the potential for strong land-atmosphere coupling and large SMAP DA 
a)

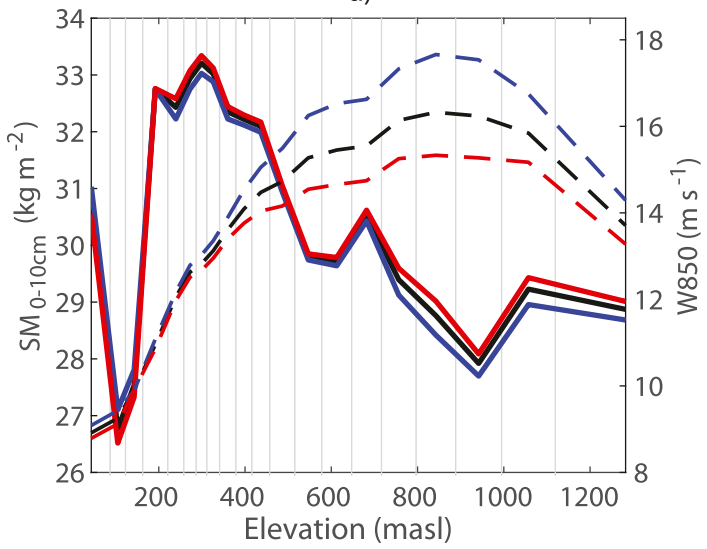

b)

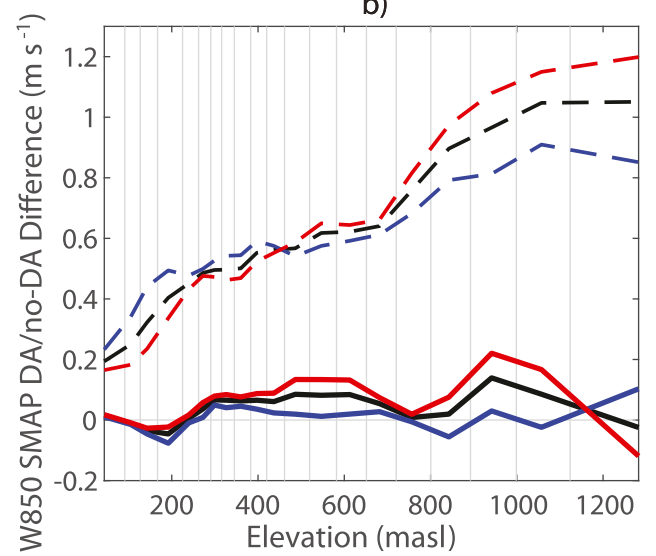

a)

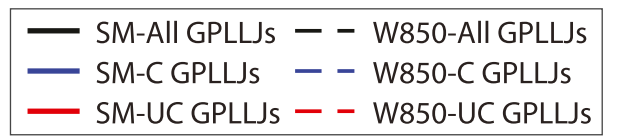

c)

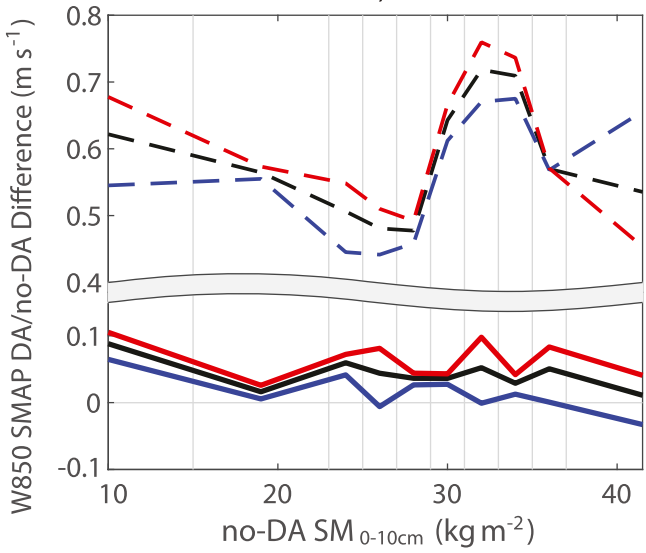

d)

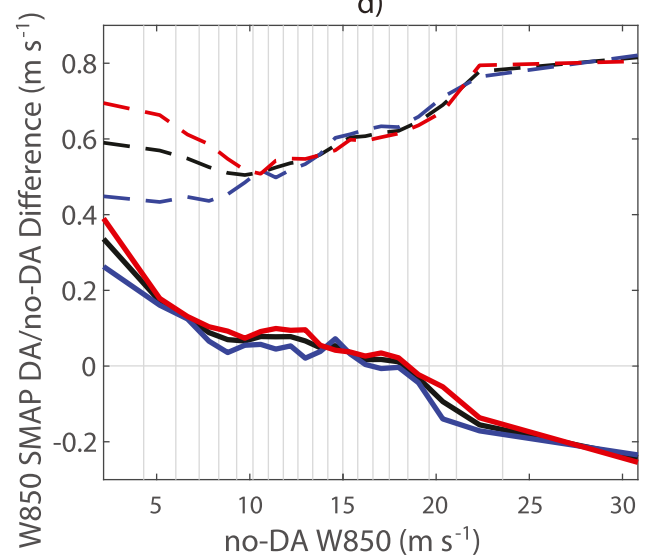

b-d) $\begin{aligned} & -\mu \text {-All GPLLJs }-- \text { MAD-All GPLLJs } \\ & -\mu \text {-C GPLLJs }-- \text { MAD-C GPLLJs } \\ & -\mu \text {-UC GPLLs }-- \text { MAD-UC GPLIs }\end{aligned}$

FIG. 10. (a) Mean WRF no-DA 1300 UTC SM $_{0-10 \mathrm{~cm}}$ and 0900 UTC W850 as a function of elevation. Also shown is mean $(\mu)$ WRF SMAP DA minus no-DA 0900 UTC W850 and MAD as a function of (b) elevation, (c) no-DA $\mathrm{SM}_{0-10 \mathrm{~cm}}$, and (d) no-DA 0900 UTC W850. Colored lines chart the bin means of the 75-jet total (black), 32-jet coupled GPLLJ (blue), and 43-jet uncoupled GPLLJ (red) samples. All land grids within the SCP are included. For elevation [(a) and (b)] and W850 [(d)] the bins are sized at $5 \%$ of the sample size, whereas for $\mathrm{SM}_{0-10 \mathrm{~cm}}[(\mathrm{c})]$ the bin sizes average $10 \%$ of the sample size. Vertical gray lines denote the bin edges.

impacts (e.g., Dirmeyer and Halder 2017). Overall, SMAP DA tends to decrease soil moisture and increase winds, which serves to reduce NU-WRF's negative wind speed bias relative to RAP analysis (Figs. 3, 4).
The placement, timing, and range of SMAP DA-related sensitivities obtained through real case studies herein are consistent with those estimated by Campbell et al. (2019) in an idealized low-level jet experiment using prescribed soil

TABLE 5. Summary of true geographic sector midpoints for this study's coupled (C) and uncoupled (UC) GPLLJ samples. Two midpoint estimates are provided: the first is based on sector centers only, regardless of whether they fall within the modeled domain, and the second is based on only those grids/data pairs included in the analysis (i.e., all land grids below the 850-hPa pressure level within both the $345-\mathrm{km}$ jet sector radius and the modeled domain).

\begin{tabular}{|c|c|c|c|c|c|c|}
\hline & \multicolumn{2}{|c|}{ Entrance } & \multicolumn{2}{|c|}{ Core } & \multicolumn{2}{|c|}{ Exit } \\
\hline & C GPLLJ & UC GPLLJ & C GPLLJ & UC GPLLJ & C GPLLJ & UC GPLLJ \\
\hline \multicolumn{7}{|c|}{ Computed from sector centers only } \\
\hline Lat & 27.43 & 27.93 & 39.32 & 38.45 & 45.62 & 43.25 \\
\hline Lon & -102.81 & -102.67 & -99.33 & -99.14 & -94.43 & -94.87 \\
\hline \multicolumn{7}{|c|}{ Computed from contributing grids within sector radius and modeled domain } \\
\hline Lat & 29.46 & 30.33 & 39.51 & 38.61 & 43.10 & 42.58 \\
\hline Lon & -102.25 & -101.92 & -99.10 & -98.97 & -94.63 & -95.05 \\
\hline
\end{tabular}


TABLE 6. Summary of the mean elevation, 2100 UTC Day 0 PBLH, and 1300 UTC Day $0 \mathrm{SM}_{0-10 \mathrm{~cm}}$ for each GPLLJ sector and the SCP, for the coupled (C) GPLLJ, uncoupled (UC) GPLLJ, and all GPLLJ samples (see Table 1 for sample sizes). Boldfaced statistics are significantly different between jet classes at the $\alpha=0.1$ level. See Figs. S9-S11 in the online supplemental material for the full histograms.

\begin{tabular}{|c|c|c|c|}
\hline Sector & C GPLLJs only & UC GPLLJs only & All GPLLJs \\
\hline \multicolumn{4}{|c|}{ Elevation (m) } \\
\hline SCP & 498 & 498 & 498 \\
\hline Entrance & 887 & 865 & 873 \\
\hline Core & 673 & 676 & 675 \\
\hline Exit & 499 & 444 & 465 \\
\hline \multicolumn{4}{|c|}{ PBLH (m) } \\
\hline SCP & 1512 & 1630 & 1579 \\
\hline Entrance & 1986 & 2042 & 2021 \\
\hline Core & 1333 & 1565 & 1467 \\
\hline Exit & 1184 & 1238 & 1219 \\
\hline \multicolumn{4}{|c|}{$\mathrm{SM}_{0-10 \mathrm{~cm}}\left(\mathrm{~kg} \mathrm{~m}^{-2}\right)$} \\
\hline SCP & 30.5 & 30.6 & 30.6 \\
\hline Entrance & 26.7 & 27.0 & 26.9 \\
\hline Core & 29.2 & 29.3 & 29.3 \\
\hline Exit & 29.6 & 31.0 & 30.5 \\
\hline
\end{tabular}

moisture extremes. Jointly, the studies demonstrate the ability of regional soil moisture differences to significantly modify sensible and severe weather parameters in a low-level jet environment. A clear potential benefit of improved wind speed estimates during jet events and their commonly associated severe weather outbreaks is higher-accuracy wind damage risk assessments. Another potential benefit is improved forecasts of wind energy ramp-up and ramp-down events.

Important is that the magnitude and sign of the SMAP DA forecast increment can vary significantly according to whether the jet is coupled or uncoupled to the upper-level atmospheric circulation. For example, of the jets considered, uncoupled jets tend to be strengthened at their exit sector (i.e., extended in length) whereas coupled jets tend to be weakened at their exit sector (i.e., shortened), which is related to SMAP DA-induced increases and decreases in daytime PBLH, respectively (Figs. 5, 8, 9). Overall, SMAP DA-induced differences are largest in the case of uncoupled jets for all land-atmospheric variable fields investigated except precipitation. On physical grounds, this result is expected because uncoupled jets have weaker large-scale forcing.

These initial jet-relative analyses of SMAP DA forecast contributions provide a solid foundation for additional followon studies. From a process-understanding standpoint, large ensemble idealized studies (e.g., Judt and Chen 2016) are required to further probe uncoupled and coupled jet differences. For example, uncoupled jets tend to be weaker jets to begin with (Burrows et al. 2020) and tend to occur in June-August when it is dry and soil moisture variability, and likely, SMAP DA's added value is low. Future process-level sensitivity analyses will target improved understanding and characterization of the regional source(s) and scales of soil moisture/surface temperature gradient-induced variability in both uncoupled and coupled jet events. This study also revealed important
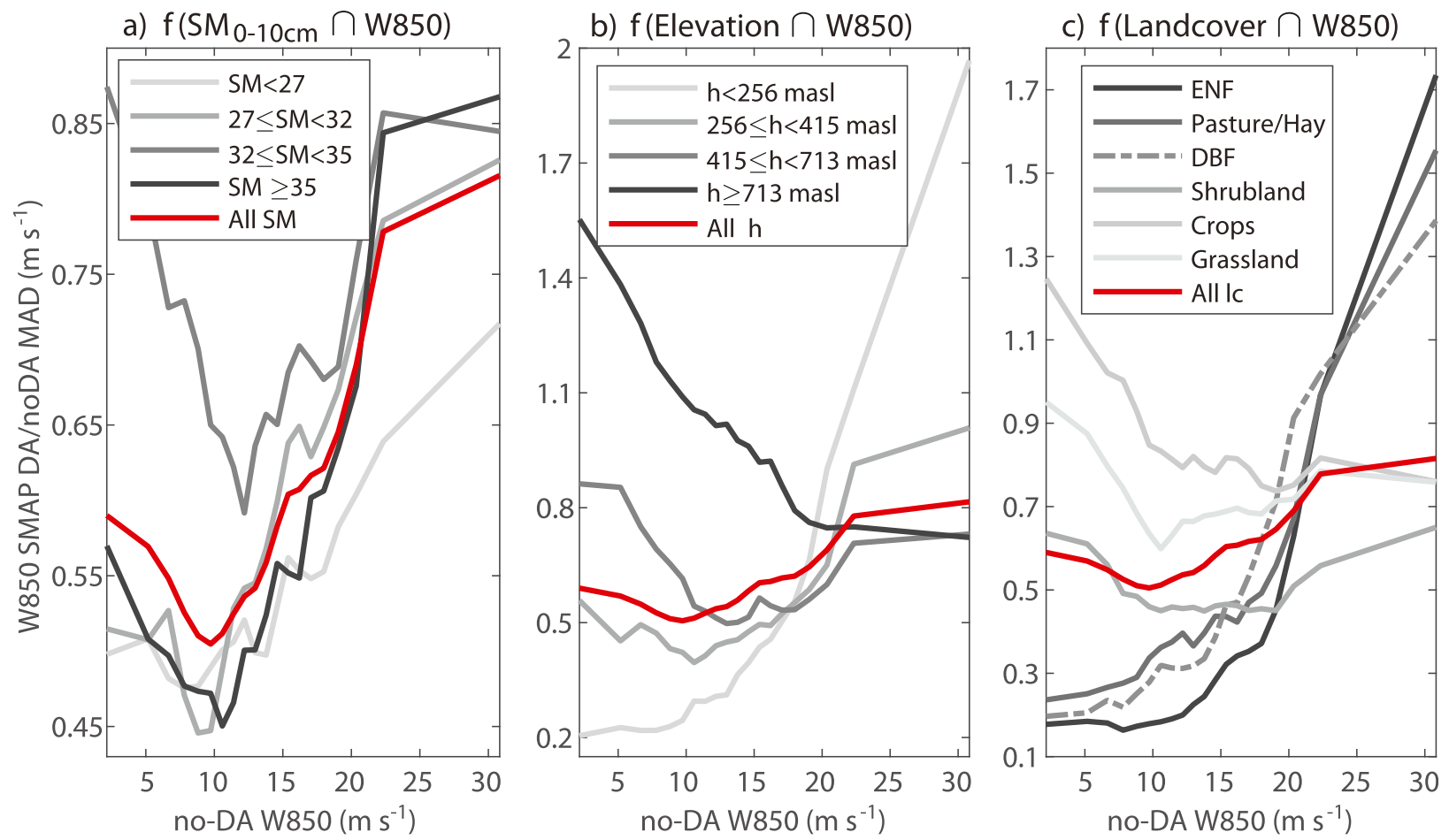

FIG. 11. MAD between WRF SMAP DA and no-DA 0900 UTC W850 over the SCP as a function of no-DA W850 partitioned by (a) $\mathrm{SM}_{0-10 \mathrm{~cm}}$, (b) elevation $h$, and (c) NLCD40 land-cover class (lc) for the total 75-jet sample. $\mathrm{SM}_{0-10 \mathrm{~cm}}$ and elevation subsamples (e.g., $\mathrm{SM}_{0-10 \mathrm{~cm}}<$ $27 \mathrm{~kg} \mathrm{~m}^{-2}$ ) correspond to quantiles of their total SCP distribution. In (c), the number of grids per lc is 817 for evergreen needleleaf forest (ENF), 2344 for pasture/hay, 929 for deciduous broadleaf forest (DBF), 2512 for shrubland, 3671 for crops, and 4358 for grassland. 
variations in the timing and magnitude of SMAP DA effects along the jet axis which will need to be further investigated and may ultimately necessitate varying the time of analysis for each jet sector. Moving radially outward from the jet axis, mean absolute wind speed differences due to SMAP DA decrease linearly (Fig. S13 in the online supplemental material).

Future modeling experiments will minimally 1) include a larger number of jet cases (e.g., $n>300$ ), 2) continuously track and define low-level jet sectors within WRF, 3) include the more physically representative Noah-MP land scheme (Niu et al. 2011; Yang et al. 2011), and 4) be conducted over an expanded modeling domain that captures the full south-north extent of the GPLLJ corridor (i.e., $20^{\circ}-60^{\circ} \mathrm{N}$ ). Optimally, the next experiment will include multisensor and multivariate land DA (e.g., Kumar et al. 2019) in a strongly coupled modeling system. For example, it would be desirable to assimilate vegetation optical depth and soil moisture retrievals from both SMAP and SMOS. Lin and Pu (2019) found that although weakly coupled SMAP DA, as implemented in this study, has a beneficial impact on forecast RMSE and bias of 2-m temperature and humidity over the Great Plains, the benefit of strongly coupled SMAP DA is even greater. Thus, it is important to conclude by stating that the jet sector-relative SMAP DA-induced forecast differences presented here using weakly coupled DA are likely underestimates of the potential SMAP DA impact on GPLLJ simulations.

Acknowledgments. This research was supported by NASA Grant NNX16AM13G. CF conceived the study, conducted the analyses, produced all figures, and wrote the manuscript. SA performed the LIS-offline and NU-WRF simulations. GX performed the LIS SMAP DA simulations. MB led LIS code modification and integration. All authors contributed to discussing and editing of the manuscript. We gratefully acknowledge assistance from Carlos Cruz, Sujay Kumar, David Mocko, and Joseph Santanello of the NU-WRF/LIS teams. All simulations were conducted on the NASA Pleiades supercomputer supported by the NASA High-End Computing (HEC) Program through the NASA Advanced Supercomputing (NAS) Division at Ames Research Center.

Data availability statement. SMAP Enhanced L3 Radiometer Global Daily 9 km EASE-Grid Soil Moisture (SPL3SMP_E) Version 2 (CRID = R16020) data were obtained from the National Snow and Ice Data Center. NCEP Operational RAP Version 2 analyses for 2015 were obtained from the NCDC archive (ftp://nomads.ncdc.noaa.gov/RUC/analysis_only). NCEP Operational RAP Version 2 and 3 analyses after March 2016 were obtained in real time by FTP ftp://ftpprd.ncep.noaa.gov/pub/data/ nccf/com/rap/prod). ESRL Experimental RAP Version 3 analyses were obtained from Robert Lipschutz of NOAA/ESRL/ GSD. MODIS MCD43GF data were obtained from Crystal Schaaf via FTP (ftp://rsftp.eeos.umb.edu/data02/Gapfilled/). MERRA-2 (inst3_3 d_asm_Np; doi: 10.5067/QBZ6MG944HW0) and all other MODIS data were obtained from the NASA Goddard Earth Sciences Data and Information Services Center via Earthdata (https://earthdata.nasa.gov/). GDAL v1.7.3 gdalwarp and gdal_translate programs were used to reproject and spatially interpolate MODIS sinusoidal projection tiled data onto a WGS84 regular lat/lon grid. Wgrib2 was used to compute Earth-relative RAP winds; NCL v6.4 (wrf_user_vert_interp) was used to interpolate WRF native level output to pressure levels. The jet tracking code was written by $\mathrm{CF}$ in Matlab v2018a and is available upon request.

\section{REFERENCES}

Agrawal, S., A. Chakraborty, N. Karmakar, S. Moulds, A. Mijic, and W. Buytaert, 2019: Effects of winter and summer-time irrigation over Gangetic Plain on the mean and intra-seasonal variability of Indian summer monsoon. Climate Dyn., 53, 31473166, https://doi.org/10.1007/s00382-019-04691-7.

Arcand, S., L. Luo, S. Zhong, L. Pei, X. Bian, and J. A. Winkler, 2019: Modeled changes to the Great Plains low-level jet under a realistic irrigation application. Atmos. Sci. Lett., 20, e888, https://doi.org/10.1002/asl.888.

Baugh, C., P. de Rosnay, H. Lawrence, T. Jurlina, M. Drusch, E. Zsoter, and C. Prudhomme, 2020: The impact of SMOS soil moisture data assimilation within the operational Global Flood Awareness System (GloFAS). Remote Sens., 12, 1490, https://doi.org/10.3390/rs12091490.

Beljaars, A. C. M., P. Viterbo, M. J. Miller, and A. K. Betts, 1996: The anomalous rainfall over the United States during July 1993: Sensitivity to land surface parameterization and soil moisture. Mon. Wea. Rev., 124, 362-383, https://doi.org/10.1175/ 1520-0493(1996)124<0362:TAROTU > 2.0.CO;2.

Benjamin, S. G., and Coauthors, 2016: A North American hourly assimilation and model forecast cycle: The Rapid Refresh. Mon. Wea. Rev., 144, 1669-1694, https://doi.org/10.1175/MWRD-15-0242.1.

Blackadar, A. K., 1957: Boundary layer wind maxima and their significance for the growth of nocturnal inversions. Bull. Amer. Meteor. Soc., 38, 283-290, https://doi.org/10.1175/15200477-38.5.283.

Blunden, J., 2017: U.S. drought monitor for 15 August 2017. NOAA/NCEI Doc., 1 pp., https://droughtmonitor.unl.edu/ data/pdf/20170815/20170815_usdm.pdf.

Bonner, W. D., 1968: Climatology of the low level jet. Mon. Wea. Rev., 96, 833-850, https://doi.org/10.1175/1520-0493(1968) 096<0833:COTLLJ > 2.0.CO;2.

Burgers, G., P. Jan van Leeuwen, and G. Evensen, 1998: Analysis scheme in the ensemble Kalman filter. Mon. Wea. Rev., 126, 1719-1724, https://doi.org/10.1175/1520-0493(1998)126<1719: ASITEK $>2.0 . \mathrm{CO} ; 2$.

Burrows, D. A., C. R. Ferguson, M. A. Campbell, G. Xia, and L. F. Bosart, 2019: An objective classification and analysis of upperlevel coupling to the Great Plains low-level jet over the twentieth century. J. Climate, 32, 7127-7152, https://doi.org/ 10.1175/JCLI-D-18-0891.1.

,-- , and L. F. Bosart, 2020: The role of upper-level coupling on Great Plains low-level jet structure and variability. J. Atmos. Sci., https://doi.org/10.1175/JAS-D-20-0059.1, in press.

Campbell, M. A., C. R. Ferguson, D. A. Burrows, M. Beauharnois, G. Xia, and L. F. Bosart, 2019: Diurnal effects of regional soil moisture anomalies on the Great Plains low-level jet. Mon. Wea. Rev., 147, 4611-4631, https://doi.org/10.1175/MWR-D-19-0135.1.

Chen, F., W. T. Crow, R. Bindlish, A. Colliander, M. S. Burgin, J. Asanuma, and K. Aida, 2018: Global-scale evaluation of SMAP, SMOS and ASCAT soil moisture products using triple collocation. Remote Sens. Environ., 214, 1-13, https://doi.org/ 10.1016/j.rse.2018.05.008. 
Chen, T. C., and J. A. Kpaeyeh, 1993: The synoptic-scale environment associated with the low-level jet of the Great Plains. Mon. Wea. Rev., 121, 416-420, https://doi.org/10.1175/15200493(1993) $121<0416$ :TSSEAW > 2.0.CO;2.

Day, G. N., 1985: Extended streamflow forecasting using NWSRFS. J. Water Resour. Plann. Manage., 111, 157-170, https://doi.org/ 10.1061/(ASCE)0733-9496(1985)111:2(157).

de Lannoy, G. J. M., P. de Rosnay, and R. H. Reichle, 2016: Soil moisture data assimilation. Handbook of Hydrometeorological Ensemble Forecasting, Q. Duan et al., Eds., Springer, 1-43.

Didan, K., 2015a: MOD13Q1: MODIS/Terra vegetation indices 16-day L3 global $250 \mathrm{~m}$ SIN grid V006. NASA LP DAAC, accessed 23 April 2019, https://www.doi.org/10.5067/MODIS/ MOD13Q1.006.

- 2015b: MYD13Q1: MODIS/Aqua vegetation indices 16-day L3 global $250 \mathrm{~m}$ SIN grid. NASA LP DAAC, accessed 23 April 2019, http://doi.org/10.5067/MODIS/MYD13Q1.006.

Dirmeyer, P. A., and K. L. Brubaker, 1999: Contrasting evaporative moisture sources during the drought of 1988 and the flood of 1993. J. Geophys. Res., 104, 19383-19397, https://doi.org/ 10.1029/1999JD900222.

, and S. Halder, 2017: Application of the land-atmosphere coupling paradigm to the operational Coupled Forecast System, version 2 (CFSv2). J. Hydrometeor., 18, 85-108, https://doi.org/10.1175/JHM-D-16-0064.1.

$\longrightarrow,-$, and R. Bombardi, 2018: On the harvest of predictability from land states in a global forecast model. J. Geophys. Res. Atmos., 123, 13 111-13 127, https://doi.org/10.1029/2018JD029103.

Draper, C. S., and R. H. Reichle, 2019: Assimilation of satellite soil moisture for improved atmospheric reanalyses. Mon. Wea. Rev., 147, 2163-2188, https://doi.org/10.1175/MWR-D-18-0393.1.

, G. J. M. De Lannoy, and Q. Liu, 2012: Assimilation of passive and active microwave soil moisture retrievals. Geophys. Res. Lett., 39, L04401, https://doi.org/10.1029/2011GL050655.

Du, Y., and R. Rotunno, 2014: A simple analytical model of the nocturnal low-level jet over the Great Plains of the United States. J. Atmos. Sci., 71, 3674-3683, https://doi.org/10.1175/ JAS-D-14-0060.1.

Ek, M. B., K. E. Mitchell, Y. Lin, E. Rogers, P. Grunmann, V. Koren, G. Gayno, and J. D. Tarpley, 2003: Implementation of Noah land surface model advances in the National Centers for Environmental Prediction operational mesoscale Eta model. J. Geophys. Res., 108, 8851, https://doi.org/10.1029/ 2002JD003296.

Entekhabi, D., and Coauthors, 2014: SMAP Handbook: Mapping soil moisture and freeze/thaw from space. Jet Propulsion Laboratory, 182 pp., https://smap.jpl.nasa.gov/.

Evensen, G., 1994: Sequential data assimilation with a nonlinear quasi-geostrophic model using Monte Carlo methods to forecast error statistics. J. Geophys. Res. Oceans, 99, 10143 10 162, https://doi.org/10.1029/94JC00572.

Fast, J. D., and M. D. McCorcle, 1990: A two-dimensional numerical sensitivity study of the Great Plains low-level jet. Mon. Wea. Rev., 118, 151-164, https://doi.org/10.1175/1520-0493(1990) $118<0151$ :ATDNSS $>2.0 . \mathrm{CO} ; 2$.

Findell, K. L., and E. A. B. Eltahir, 2003: Atmospheric controls on soil moisture-boundary layer interactions. Part I: Framework development. J. Hydrometeor., 4, 552-569, https://doi.org/ 10.1175/1525-7541(2003)004<0552:ACOSML>2.0.CO;2.

Ford, T. W., A. D. Rapp, and S. M. Quiring, 2015: Does afternoon precipitation occur preferentially over dry or wet soils in Oklahoma? J. Hydrometeor., 16, 874-888, https://doi.org/10.1175/ JHM-D-14-0005.1.
Frye, J. D., and T. L. Mote, 2010: Convection initiation along soil moisture boundaries in the southern Great Plains. Mon. Wea. Rev., 138, 1140-1151, https://doi.org/10.1175/2009MWR2865.1.

Gelaro, R., and Coauthors, 2017: The Modern-Era Retrospective Analysis for Research and Applications, version 2 (MERRA-2). J. Climate, 30, 5419-5454, https://doi.org/10.1175/JCLI-D-160758.1.

Gruber, A., T. Scanlon, R. van der Schalie, W. Wagner, and W. Dorigo, 2019: Evolution of the ESA CCI soil moisture climate data records and their underlying merging methodology. Earth Syst. Sci. Data, 11, 717-739, https://doi.org/10.5194/ essd-11-717-2019.

Holton, J. R., 1967: The diurnal boundary layer wind oscillation above sloping terrain. Tellus, 19, 199-205, https://doi.org/10.1111/ j.2153-3490.1967.tb01473.x.

Hong, S. Y., Y. Noh, and J. Dudhia, 2006: A new vertical diffusion package with an explicit treatment of entrainment processes. Mon. Wea. Rev., 134, 2318-2341, https://doi.org/10.1175/ MWR3199.1.

Houze, R. A., Jr., 2018: 100 years of research on mesoscale convective systems. A Century of Progress in Atmospheric and Related Sciences: Celebrating the American Meteorological Society Centennial, Meteor. Monogr., No. 59, Amer. Meteor. Soc., https://doi.org/10.1175/AMSMONOGRAPHS-D-18-0001.1.

Iacono, M. J., J. S. Delamere, E. J. Mlawer, M. W. Shephard, S. A. Clough, and W. D. Collins, 2008: Radiative forcing by longlived greenhouse gases: Calculations with the AER radiative transfer models. J. Geophys. Res., 113, D13103, https://doi.org/ 10.1029/2008JD009944.

Jackson, T., and Coauthors, 2018: Calibration and validation for the L2/3_SM_P version 5 and L2/3_SM_P_E version 2 data products. SMAP Project, JPL D-56297, Jet Propulsion Laboratory, Pasadena, CA, 44 pp., https://nsidc.org/sites/ nsidc.org/files/technical-references/L2SMPE_Asmt_Rpt_EOPM_ v5c_Jun2018.pdf.

Jiménez, P. A., J. Dudhia, J. F. González-Rouco, J. Navarro, J. P. Montávez, and E. García-Bustamante, 2012: A revised scheme for the WRF surface layer formulation. Mon. Wea. Rev., 140, 898-918, https://doi.org/10.1175/MWR-D-11-00056.1.

Judt, F., and S. S. Chen, 2016: Predictability and dynamics of tropical cyclone rapid intensification deduced from highresolution stochastic ensembles. Mon. Wea. Rev., 144, 43954420, https://doi.org/10.1175/MWR-D-15-0413.1.

Karthikeyan, L., M. Pan, N. Wanders, D. N. Kumar, and E. F. Wood, 2017: Four decades of microwave satellite soil moisture observations: Part I. A review of retrieval algorithms. Adv. Water Resour., 109, 106-120, https://doi.org/10.1016/ j.advwatres.2017.09.006.

Kerr, Y. H., and Coauthors, 2016: Overview of SMOS performance in terms of global soil moisture monitoring after six years in operation. Remote Sens. Environ., 180, 40-63, https://doi.org/ 10.1016/j.rse.2016.02.042.

Kim, H., R. Parinussa, A. G. Konings, W. Wagner, M. H. Cosh, V. Lakshmi, M. Zohaib, and M. Choi, 2018: Global-scale assessment and combination of SMAP with ASCAT (active) and AMSR2 (passive) soil moisture products. Remote Sens. Environ., 204, 260-275, https://doi.org/10.1016/j.rse.2017.10.026.

Koster, R. D., and S. P. P. Mahanama, 2012: Land surface controls on hydroclimatic means and variability. J. Hydrometeor., 13, 1604-1620, https://doi.org/10.1175/JHM-D-12-050.1.

, and Coauthors, 2004: Regions of strong coupling between soil moisture and precipitation. Science, 305, 1138-1140, https:// doi.org/10.1126/science.1100217. 
Kumar, S. V., and Coauthors, 2006: Land information system: An interoperable framework for high resolution land surface modeling. Environ. Modell. Software, 21, 1402-1415, https:// doi.org/10.1016/j.envsoft.2005.07.004.

, and Coauthors, 2014: Assimilation of remotely sensed soil moisture and snow depth retrievals for drought estimation. J. Hydrometeor., 15, 2446-2469, https://doi.org/10.1175/JHMD-13-0132.1.

—, C. D. Peters-Lidard, J. A. Santanello, R. H. Reichle, C. S. Draper, R. D. Koster, G. Nearing, and M. F. Jasinski, 2015: Evaluating the utility of satellite soil moisture retrievals over irrigated areas and the ability of land data assimilation methods to correct for unmodeled processes. Hydrol. Earth Syst. Sci., 19, 4463-4478, https://doi.org/10.5194/hess-19-4463-2015.

—, P. A. Dirmeyer, C. D. Peters-Lidard, R. Bindlish, and J. Bolten, 2018: Information theoretic evaluation of satellite soil moisture retrievals. Remote Sens. Environ., 204, 392-400, https://doi.org/10.1016/j.rse.2017.10.016.

—, M. Jasinski, D. M. Mocko, M. Rodell, J. Borak, B. Li, H. K. Beaudoing, and C. D. Peters-Lidard, 2019: NCA-LDAS land analysis: Development and performance of a multisensor, multivariate land data assimilation system for the National Climate Assessment. J. Hydrometeor., 20, 1571-1593, https:// doi.org/10.1175/JHM-D-17-0125.1.

Lakshmanan, V., and T. W. Humphrey, 2014: A map reduce technique to mosaic continental-scale weather radar data in real-time. IEEE J-Stars, 7, 721-732, https://doi.org/10.1109/ JSTARS.2013.2282040.

Laloyaux, P., and Coauthors, 2018: CERA-20C: A coupled reanalysis of the twentieth century. J. Adv. Model. Earth Syst., 10, 1172-1195, https://doi.org/10.1029/2018MS001273.

Lievens, H., and Coauthors, 2015: SMOS soil moisture assimilation for improved hydrologic simulation in the Murray Darling Basin, Australia. Remote Sens. Environ., 168, 146-162, https:// doi.org/10.1016/j.rse.2015.06.025.

Lin, L.-F., and Z. Pu, 2018: Characteristics of background error covariance of soil moisture and atmospheric states in strongly coupled land-atmosphere data assimilation. J. Appl. Meteor. Climatol., 57, 2507-2529, https://doi.org/10.1175/JAMC-D-180050.1 .

— , and - 2019: Examining the impact of SMAP soil moisture retrievals on short-range weather prediction under weakly and strongly coupled data assimilation with WRF-Noah. Mon. Wea. Rev., 147, 4345-4366, https://doi.org/10.1175/MWR-D19-0017.1.

— , and — 2020: Improving near-surface short-range weather forecasts using strongly coupled land-atmosphere data assimilation with GSI-EnKF. Mon. Wea. Rev., 148, 2863-2888, https://doi.org/10.1175/MWR-D-19-0370.1.

Mahanama, S. P. P., R. D. Koster, R. H. Reichle, and L. Zubair, 2008: The role of soil moisture initialization in subseasonal and seasonal streamflow prediction-A case study in Sri Lanka. Adv. Water Resour., 31, 1333-1343, https://doi.org/10.1016/ j.advwatres.2008.06.004.

Maurer, E. P., and D. P. Lettenmaier, 2003: Predictability of seasonal runoff in the Mississippi River basin. J. Geophys. Res., 108, 8607, https://doi.org/10.1029/2002JD002555.

Miralles, D. G., P. Gentine, S. I. Seneviratne, and A. J. Teuling, 2019: Land-atmospheric feedbacks during droughts and heatwaves: State of the science and current challenges. Ann. N. Y. Acad. Sci., 1436, 19-35, https://doi.org/10.1111/nyas.13912.

Montini, T. L., C. Jones, and L. M. V. Carvalho, 2019: The South American low-level jet: A new climatology, variability, and changes. J. Geophys. Res. Atmos., 124, 1200-1218, https:// doi.org/10.1029/2018JD029634.

Myneni, R., Y. Knyazikhin, and T. Park, 2015: MCD15A3H MODIS/Terra + Aqua leaf area index/FPAR 4-day L4 global 500m SIN grid V006. NASA EOSDIS Land Processes DAAC, accessed 13 August 2018, http://doi.org/10.5067/ MODIS/MCD15A3H.006.

Namias, J., 1960: Factors in the initiation, perpetuation and termination of drought. Extract of Publ. 51, International Association of Hydrological Sciences (IAHS) Commission of Surface Waters, 81-94.

Niu, G. Y., and Coauthors, 2011: The community Noah land surface model with multiparameterization options (Noah-MP): 1. Model description and evaluation with local-scale measurements. J. Geophys. Res., 116, D12109, https://doi.org/ 10.1029/2010JD015139.

Njoku, E. G., and D. Entekhabi, 1996: Passive microwave remote sensing of soil moisture. J. Hydrol., 184, 101-129, https:// doi.org/10.1016/0022-1694(95)02970-2.

_, T. J. Jackson, V. Lakshmi, T. K. Chan, and S. V. Nghiem, 2003: Soil moisture retrieval from AMSR-E. IEEE Trans. Geosci. Remote Sens., 41, 215-229, https://doi.org/10.1109/ TGRS.2002.808243.

O’Neill, P. E., S. Chan, E. Njoku, T. Jackson, and R. Bindlish, 2018: SMAP Enhanced L3 Radiometer Global Daily $9 \mathrm{~km}$ EASE-Grid Soil Moisture, version 2 [R16020]. Accessed 7 October 2019, https://doi.org/10.5067/RFKIZ5QY5ABN.

—, R. Bindlish, S. Chan, J. Chaubell, E. Njoku, and T. Jackson, 2020: SMAP Algorithm Theoretical Basis Document: Level 2 \& 3 Soil Moisture (Passive) Data Products. Jet Propulsion Laboratory Doc. JPL D-66480, 100 pp., https://nsidc.org/sites/nsidc.org/files/ technical-references/ATBD_SPL23_SMP_E_RevF.pdf.

Pan, M., X. T. Cai, N. W. Chaney, D. Entekhabi, and E. F. Wood, 2016: An initial assessment of SMAP soil moisture retrievals using high-resolution model simulations and in situ observations. Geophys. Res. Lett., 43, 9662-9668, https://doi.org/10.1002/ 2016 GL069964.

Parish, T. R., 2017: On the forcing of the summertime Great Plains low-level jet. J. Atmos. Sci., 74, 3937-3953, https://doi.org/ 10.1175/JAS-D-17-0059.1.

Peters-Lidard, C. D., and Coauthors, 2007: High-performance Earth system modeling with NASA/GSFC's land information system. Innov. Syst. Software Eng., 3, 157-165, https://doi.org/ 10.1007/s11334-007-0028-x.

_ , and Coauthors, 2015: Integrated modeling of aerosol, cloud, precipitation and land processes at satellite-resolved scales. Environ. Modell. Software, 67, 149-159, https://doi.org/10.1016/ j.envsoft.2015.01.007.

Rasmussen, S. H., J. H. Christensen, M. Drews, D. J. Gochis, and J. C. Refsgaard, 2012: Spatial-scale characteristics of precipitation simulated by regional climate models and the implications for hydrological modeling. J. Hydrometeor., 13, 1817-1835, https://doi.org/10.1175/JHM-D-12-07.1.

Reichle, R. H., and R. D. Koster, 2004: Bias reduction in short records of satellite soil moisture. Geophys. Res. Lett., 31, L19501, https://doi.org/10.1029/2004GL020938.

- - - - , P. Liu, S. P. P. Mahanama, E. G. Njoku, and M. Owe, 2007: Comparison and assimilation of global soil moisture retrievals from the Advanced Microwave Scanning Radiometer for the Earth observing system (AMSR-E) and the Scanning Multichannel Microwave Radiometer (SMMR). J. Geophys. Res., 112, D09108, https://doi.org/ 10.1029/2006JD008033. 
Ryu, D., W. T. Crow, X. Zhan, and T. J. Jackson, 2009: Correcting unintended perturbation biases in hydrologic data assimilation. J. Hydrometeor., 10, 734-750, https://doi.org/10.1175/ 2008JHM1038.1.

Santanello, J. A., and Coauthors, 2018: Land-atmosphere interactions: The LoCo perspective. Bull. Amer. Meteor. Soc., 99, 1253-1272, https://doi.org/10.1175/BAMS-D-17-0001.1.

Seneviratne, S. I., T. Corti, E. L. Davin, M. Hirschi, E. B. Jaeger, I. Lehner, B. Orlowsky, and A. J. Teuling, 2010: Investigating soil moisture-climate interactions in a changing climate: A review. Earth-Sci. Rev., 99, 125-161, https://doi.org/10.1016/ j.earscirev.2010.02.004.

Shapiro, A., E. Fedorovich, and S. Rahimi, 2016: A unified theory for the Great Plains nocturnal low-level jet. J. Atmos. Sci., 73, 3037-3057, https://doi.org/10.1175/JAS-D-15-0307.1.

Shukla, J., and Y. Mintz, 1982: Influence of land-surface evapotranspiration on the Earth's climate. Science, 215, 1498-1501, https://doi.org/10.1126/science.215.4539.1498.

Skamarock, W. C., J. B. Klemp, J. Dudhia, D. O. Gill, D. M. Barker, W. Wang, and J. G. Powers, 2005: A description of the Advanced Research WRF version 2. NCAR Tech. Note NCAR/TN-468+STR, 88 pp., https://doi.org/10.5065/D6DZ069T.

Soldo, Y., A. Khazaal, F. Cabot, and Y. H. Kerr, 2016: An RFI index to quantify the contamination of SMOS data by radiofrequency interference. IEEE J-Stars, 9, 1577-1589, https:// doi.org/10.1109/JSTARS.2015.2425542.

Song, F., Z. Feng, L. R. Leung, R. A. H. Jr, J. Wang, J. Hardin, and C. R. Homeyer, 2019: Contrasting spring and summer largescale environments associated with mesoscale convective systems over the U.S. Great Plains. J. Climate, 32, 6749-6767, https://doi.org/10.1175/JCLI-D-18-0839.1.

Song, H.-J., C. R. Ferguson, and J. K. Roundy, 2016: Landatmosphere coupling at the Southern Great Plains Atmospheric Radiation Measurement (ARM) field site and its role in anomalous afternoon peak precipitation. J. Hydrometeor., 17, 541-556, https://doi.org/10.1175/JHM-D-15-0045.1.

Sun, Q., Z. Wang, Z. Li, A. Erb, and C. B. Schaaf, 2017: Evaluation of the global MODIS 30 arc-second spatially and temporally complete snow-free land surface albedo and reflectance anisotropy dataset. Int. J. Appl. Earth Obs. Geoinf., 58, 36-49, https://doi.org/10.1016/j.jag.2017.01.011.

Thompson, G., and T. Eidhammer, 2014: A study of aerosol impacts on clouds and precipitation development in a large winter cyclone. J. Atmos. Sci., 71, 3636-3658, https://doi.org/ 10.1175/JAS-D-13-0305.1.

Uccellini, L. W., 1980: On the role of upper tropospheric jet streaks and leeside cyclogenesis in the development of low-level jets in the Great Plains. Mon. Wea. Rev., 108, 1689-1696, https://doi.org/10.1175/1520-0493(1980)108<1689:OTROUT> 2.0.CO;2. van den Hurk, B., F. Doblas-Reyes, G. Balsamo, R. D. Koster, S. I. Seneviratne, and H. Camargo, 2012: Soil moisture effects on seasonal temperature and precipitation forecast scores in Europe. Climate Dyn., 38, 349-362, https://doi.org/10.1007/ s00382-010-0956-2.

Wang, S.-Y., and T.-C. Chen, 2009: The late-spring maximum of rainfall over the U.S. Central Plains and the role of the lowlevel jet. J. Climate, 22, 4696-4709, https://doi.org/10.1175/ 2009JCLI2719.1.

Welty, J., S. Stillman, X. Zeng, and J. Santanello, 2020: Increased likelihood of appreciable afternoon rainfall over wetter or drier soils dependent upon atmospheric dynamic influence. Geophys. Res. Lett., 48, e2020GL087779, https://doi.org/10.1029/ 2020GL087779.

Whiteman, C. D., X. D. Bian, and S. Y. Zhong, 1997: Low-level jet climatology from enhanced rawinsonde observations at a site in the southern Great Plains. J. Appl. Meteor., 36, 1363-1376, https://doi.org/10.1175/1520-0450(1997)036<1363:LLJCFE > 2.0.CO;2.

WMO, 2016: The global observing system for climate: Implementation needs. WMO, 341 pp., https://gcos.wmo.int/en/gcos-implementationplan.

Xia, Y. L., and Coauthors, 2012a: Continental-scale water and energy flux analysis and validation for North American Land Data Assimilation System project phase 2 (NLDAS-2): 2. Validation of model-simulated streamflow. J. Geophys. Res., 117, D03110, https://doi.org/10.1029/2011JD016051. and Coauthors, 2012b: Continental-scale water and energy flux analysis and validation for the North American Land Data Assimilation System project phase 2 (NLDAS-2): 1. Intercomparison and application of model products. J. Geophys. Res., 117, D03109, https://doi.org/10.1029/2011JD016048.

Yang, L., and Coauthors, 2018: A new generation of the United States national land cover database: Requirements, research priorities, design, and implementation strategies. ISPRS J. Photogramm. Remote Sens., 146, 108-123, https://doi.org/ 10.1016/j.isprsjprs.2018.09.006.

Yang, Z., and Coauthors, 2019: Irrigation impact on water and energy cycle during dry years over the United States using convection-permitting WRF and a dynamical recycling model. J. Geophys. Res. Atmos., 124, 11220-11241, https://doi.org/ 10.1029/2019JD030524.

Yang, Z. L., and Coauthors, 2011: The community Noah land surface model with multiparameterization options (NoahMP): 2. Evaluation over global river basins. J. Geophys. Res., 116, D12110, https://doi.org/10.1029/2010JD015140.

Yin, J., X. Zhan, J. Liu, and M. Schull, 2019: An intercomparison of Noah model skills with benefits of assimilating SMOPS blended and individual soil moisture retrievals. Water Resour. Res., 55, 2572-2592, https://doi.org/10.1029/2018WR024326. 